\title{
Dynamics of Human Serum Transferrin in Varying Physicochemical Conditions Explored by Using Molecular Dynamics Simulations
}

Sowmya Indrakumar ${ }^{1, a^{*}}$, Alina Kulakova ${ }^{1, b}$, Pernille Harris ${ }^{1, b}$, and Günther H. J. Peters ${ }^{1 *}$

${ }^{1}$ Technical University of Denmark, Department of Chemistry, 2800 Kgs. Lyngby, Denmark,

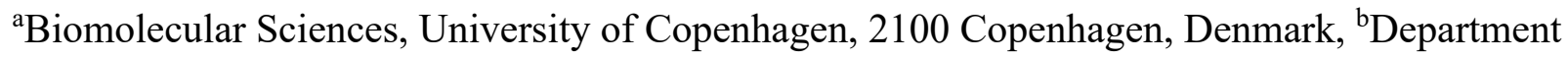
of Chemistry, University of Copenhagen, 2100 Copenhagen, Denmark 


\begin{abstract}
Conformational stability of human serum transferrin (Tf) at varying $\mathrm{pH}$, salt, and excipient concentrations were investigated using molecular dynamics (MD) simulations and the results are compared with previously published small angle X-ray scattering (SAXS) experiments. SAXS study showed that at $\mathrm{pH} 5$, Tf is predominantly present in partially open (PO) form, and the factions of PO differ based on the physicochemical condition and drifts towards closed form (HO) as the $\mathrm{pH}$ increases. Tf is a bilobal glycoprotein that is composed of homologous halves termed as Nlobe and C-lobe. The current study shows that the protonation of Y188 and K206 at pH 5 is the primary conformational drive into $\mathrm{PO}$, which shifts towards the closed $(\mathrm{HO})$ conformer as the $\mathrm{pH}$ increases. Furthermore, at pH 6.5, PO is unfavorable due to negative charge-charge repulsion at the N/C-lobe interface linker region causing increased hinge distance when compared to HO, which has favorable attractive electrostatics. Subsequently, the effect of salt concentration at 70 and $140 \mathrm{mM} \mathrm{NaCl}$ was studied. At $70 \mathrm{mM} \mathrm{NaCl}$ and $\mathrm{pH}$ 5, chloride ions bind strongly in the $\mathrm{N}-$ lobe iron-binding site, whereas these interactions are weak at $\mathrm{pH}$ 6.5. With increasing salt

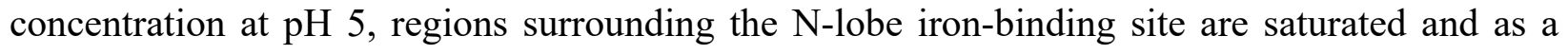
consequence sodium and chloride ions accumulate into the bulk. Additionally, protein-excipient interactions were investigated. At pH 5, excipients interact in similar loop regions, E89-T93, D416-D420, located in the C-lobe and N-lobe of the HO conformer, respectively. It is anticipated that interactions of additives in these two loop regions cause conformational changes that lead to iron coordinating residues in the N-lobe to drift away from iron and thus drive HO to PO conversion. Furthermore, at pH 6.5 and $140 \mathrm{mM}$ histidine or phosphate, these interactions are negligible leading to the stabilization of HO.
\end{abstract}




\section{INTRODUCTION}

Transferins are a family of proteins that belong to the group of non-heme ferric ion $\left(\mathrm{Fe}^{3+}\right)$ binding glycoproteins widely present in bodily fluids and cells of vertebrates.[1-3] Transferrin (Tf) which is synthesized in the liver[4] and secreted into the plasma, is the main ferric ion transporter. Tf delivers iron to target sites like the liver, the spleen, and bone marrow where it is incorporated into newly formed erythrocytes via the transferrin receptor (TfR) mediated endocytosis.[5] During endocytosis at acidic $\mathrm{pH}$, the entire Tf-TfR complex is internalized into the endosome to release ferric ion and subsequently, the complex is returned to the cell surface. Tf is then released from the complex back into the cytosol to acquire more iron.[6] Unbound ferric ions participate in redox reactions (e.g. Fenton reaction) to produce free radicals that are known to attack proteins, nucleic acids, etc. Therefore, the binding of ferric ions to $\mathrm{Tf}$ is of prime importance to creating an antibacterial, and low-iron environment.[7] Tf is an $80 \mathrm{kDa}$ bilobal glycoprotein (half-life 8-10 days) with two homologous halves termed as N-lobe and C-lobe, respectively, and each lobe binds to a ferric ion.[1] The presence of anions such as bicarbonate (BCT)[8] facilitates the binding of iron by excluding water from the coordination sites otherwise the binding is negligible.[2]

Tf's potential in a pharmaceutical application has been established. Tf supplements are recommended to treat disease conditions such as anemia and toxicity conditions of iron such as oxidative stress.[9] Apart from $\mathrm{Fe}^{3+}$, Tf has been shown to bind to other metal ions such as $\mathrm{Ga}^{3+}$, $\mathrm{In}^{3+}, \mathrm{Ti}^{4+}$, and $\mathrm{Ru}^{3+}$ for therapeutic or diagnostic applications.[10-12]

Moreover, the efficient cellular uptake pathway has been explored for targeted delivery of smallmolecule drugs, or other macromolecules by Tf.[11,13] Transferrin-conjugated drugs have shown significant improvement in cytotoxicity and selectivity of the drugs.[14] Moreover, the efficacy of the Tf-conjugated drug as an anticancer therapy has been demonstrated in the in-vitro treatment of breast cancer cells and prostate cancer cells in mouse models.[15] Additionally, Tf-conjugated drugs can cross the blood-brain barrier by receptor-mediated endocytosis targeting rat tumor cells, but not human cells posing further formulation challenges. [15-18] One of the major limitations in the development of protein therapeutics is the proper stabilization of biologics as these structures are dynamic and may have sites prone to chemical (oxidation and hydrolysis) and physical (aggregation and unfolding) degradation.[19] To overcome these challenges, excipients are used in an effort to stabilize biologics without losing their biological activity and to prevent protein- 
protein interactions that might cause protein instability[20-22] and consequently lead to insoluble aggregates. The general formulation approach is to screen for different physicochemical conditions such as $\mathrm{pH}$, excipients, and buffer systems to improve protein stability by for instance varying $\mathrm{pH}$ and/or osmolality of the solution.[23-29] To optimize protein formulation, a molecular understanding of excipient-protein interactions is pivotal and can guide scientists in designing formulations.

Several studies have been conducted on $\mathrm{Tf}$ in the line of $\mathrm{pH}$ and salt effects on protein properties.[30-32] For instance, a study showed that change in the protonation state of Y188 at low $\mathrm{pH}$ initiates iron release from the N-lobe.[30,31,33] Another study focusing on the salt effect on protein properties showed that salt accumulation starts first in the N-lobe, and iron release from the N-lobe is coordinated by N-lobe and C-lobe interactions.[32,34] To the best of our knowledge, there exists no computational study which discusses excipient and salt effects as a function of $\mathrm{pH}$ on Tf stability. To investigate the molecular origin for the preference of the different conformers at different physicochemical conditions as deduced from small angle X-ray scattering (SAXS), molecular dynamics (MD) simulations were utilized. The different physicochemical conditions were chosen based on an earlier SAXS study, which demonstrated that at low pH partially open (PO) conformer is preferred and the equilibrium shifts towards the closed conformer (HO) as the $\mathrm{pH}$ increases. [24] At low $\mathrm{pH}$, the fraction of PO differs depending on salt and excipient concentrations. In the current study, we have performed MD simulations to obtain a detailed molecular understanding of how these physicochemical conditions affect protein surface properties and conformational stability, which can be utilized in designing preventive measures of aggregation in optimizing protein formulations. 


\section{METHODOLOGY}

\section{Structure}

Several X-ray crystal structures of $\mathrm{Tf}$ are available, and they represent three different conformations, i.e. iron-bound diferric holo form (PDB ID: 3V83)[35], iron-free apo form (PDB ID: 2HAV)[6], and intermediate form termed as "partially open (PDB ID: 3QYT)[36] with N-lobe open as seen in apo form and C-lobe closed as seen in the holo form with $\mathrm{Fe}^{3+}$ bound in the two lobes. The partially open and holo-form of Tf will be referred to as $\mathrm{PO}$ and $\mathrm{HO}$, respectively, in the following. Figure 1 shows the structural architecture of $\mathrm{Tf}$ and residues coordinating with $\mathrm{Fe}^{3+}$ and BCT in the two lobes. Each lobe has two subdomains. The N-lobe consists of N'(1-95 and 247-331) and N''(96-246). The C-lobe comprises C'(339-425 and 573-679) and C''(426-572). A linker (331-339) connects both lobes. The Tf structure is stabilized by 19 cystines, and the C-lobe has an extra cystine making it more rigid compared to the $\mathrm{N}$-lobe.

A.

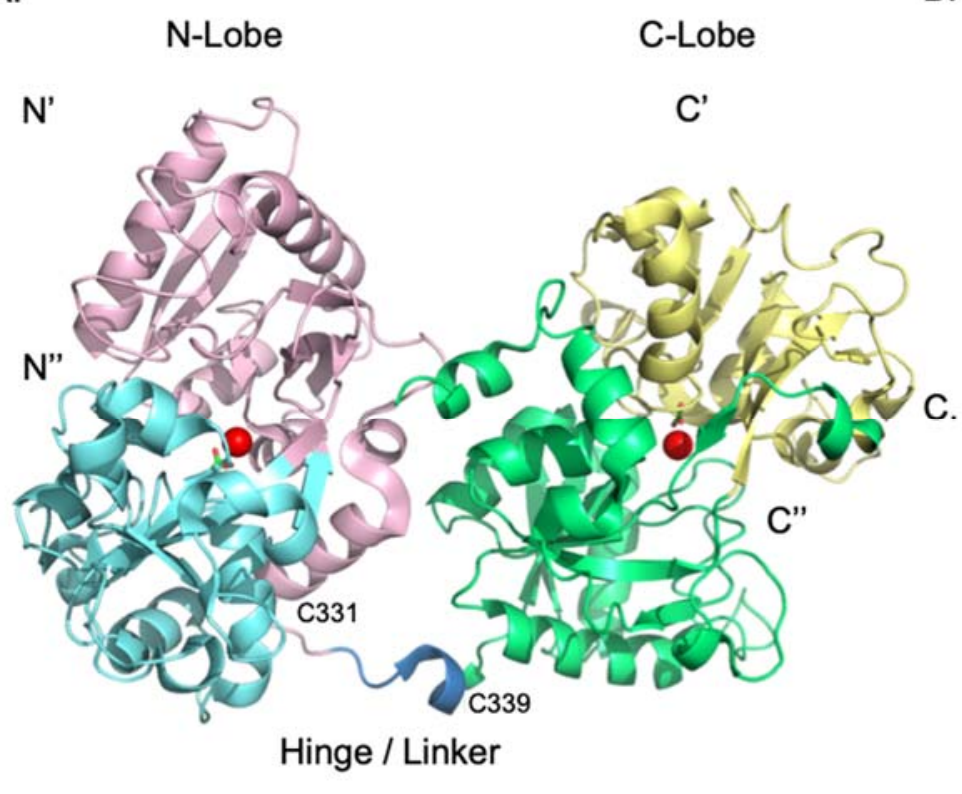

B. N-Lobe
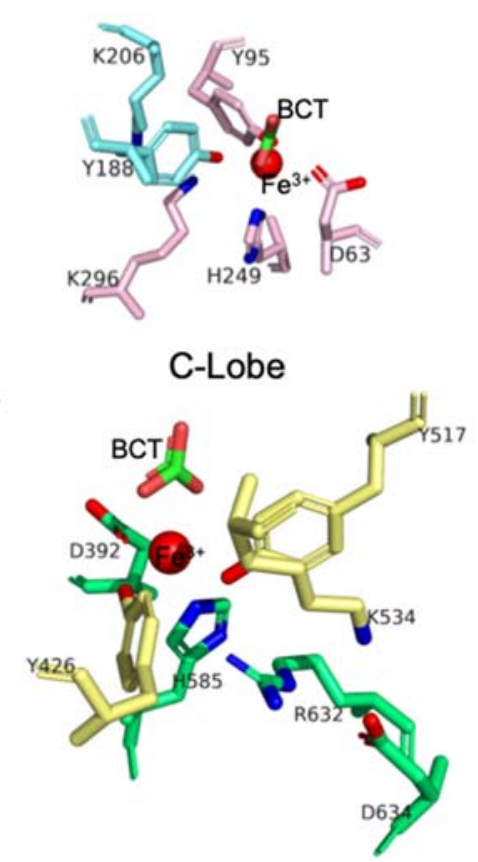

Figure 1. Structure of Tf. Color coding is as follows: pink (N'), cyan (N',), green ( C'), yellow $\left(\mathrm{C}^{\prime \prime}\right)$, and blue (linker residues 331-339)[7]. $\mathrm{Fe}^{3+}$ ions are shown as red spheres, and BCT is displayed in a stick representation, where oxygen and carbon atoms are colored in red and green, respectively. B. Coordination of the residues and $\mathrm{BCT}$ molecule with $\mathrm{Fe}^{3+}$ in the $\mathrm{N}$-lobe is displayed. Residues D63, Y95, Y188, and H249 coordinate with $\mathrm{Fe}^{3+}$, and a dilysine bridge also 
termed as 'dilysine trigger'[37] (K206, K296) constitutes the second shell residues. C. Coordination of the residues and BCT molecule with $\mathrm{Fe}^{3+}$ in the $\mathrm{C}$-lobe is depicted. Residues D392, Y426, Y517, and H585 coordinate with $\mathrm{Fe}^{3+}$, and the triad of residues, K534, R632, and D634, forms the second shell residues.

\section{Molecular dynamics simulations}

The different conformations of transferrin were subjected to MD simulations at different physicochemical conditions to investigate the conformational changes induced by $\mathrm{pH}$ change and the addition of salt and excipients. To ease the discussion, salt ions and excipients will also be referred to as additives.

1. Effect of pH. The protonation state of the titratable amino acids at $\mathrm{pH}$ values of 5 , 6.5 , and 8 was calculated using the $\mathrm{H}++$ server (http://biophysics.cs.vt.edu/H++ ).[38] The server settings were adjusted to an external dielectric constant of 80 for water, and the internal dielectric constant was set to 10.[38] The topology and coordinate files generated as output in Amber format were used to generate the PDB structure file using ambpdb tool implemented in Amber 16.[39] The PDB files were used as the starting structure for all-atom classical constant $\mathrm{pH}$ MD simulations[40] in explicit solvent. Simulations were performed with the Amber 16 program[41] employing the amber force field, ff99SB[42], for proteins. Water molecules were represented using the TIP3P[43] water model. Parameters for $\mathrm{Fe}^{3+}$ were defined using the 12-6-4 LJ-type nonbonded[44,45] model in the amber force field. The bicarbonate molecule was prepared using antechamber[46] module in Amber 16 and the AM1-BCC[47] charge method. All bonds to hydrogen atoms were constrained using the SHAKE algorithm. [48] Each system was neutralized using chloride ions (pH $5,6.5$, and 8 needed 8, 5, and 1 chloride ion(s), respectively). Each system was solvated in a truncated octahedron water box with a $15 \AA$ padding in all three Cartesian directions. The particle mesh Ewald method[49] was employed to determine the non-bonded electrostatic energies with a real-space cutoff of $8 \AA$. Each system was minimized for 5000 steps. The first 1500 steps were performed using the steepest descent method followed by the conjugate gradient method for the remaining steps. Subsequently, each system was heated linearly from $10 \mathrm{~K}$ to $300 \mathrm{~K}$ within 1 ns using the Langevin thermostat[50] with a collision frequency of $5 \mathrm{ps}^{-1}$. Berendsen barostat[51] was used to control pressure dynamics. The systems were then equilibrated for $2 \mathrm{~ns}$ at constant temperature $(300 \mathrm{~K})$ and pressure $(1 \mathrm{bar})$. Following this, a short equilibration of $2 \mathrm{~ns}$ at constant 
$\mathrm{pH}$ was performed to update the protonation of titratable residues. Only, the residues near $\mathrm{Fe}^{3+}$ were titrated during the simulation to take into account fluctuation in the protonation states. Finally, constant $\mathrm{pH}$ simulations were performed for $100 \mathrm{~ns}$, and coordinates were saved every 10 ps. Each system at a particular pH was simulated in duplicates for $100 \mathrm{~ns}$ to estimate the statistical uncertainty of the results. Different starting structures for the simulations were obtained by applying different steepest descent minimization cycles (1500 and 2000 steps).

2. Effect of Salt. The effect of 70 and $140 \mathrm{mM} \mathrm{NaCl}$ was studied at $\mathrm{pH} 5$ and 6.5. The ionic strength (IS) was adjusted to 70 and $140 \mathrm{mM} \mathrm{NaCl}$ by the addition of $126\left(\mathrm{Na}^{+}+\mathrm{Cl}^{-}\right)$, and 248 $\left(\mathrm{Na}^{+}+\mathrm{Cl}^{-}\right)$ions, respectively, to the solvated system containing $\sim 48000$ water molecules. Each system at a particular physiochemical condition of $\mathrm{pH}$ and IS was simulated in duplicates for 100 ns as described above.

3. Effect of excipients. Arginine, acetate, phosphate, and histidine were considered since those were used previously in the SAXS study on Tf stability.[24] Structures were obtained from PubChem[52] and Zinc Database[53]. These molecules were prepared at the desired $\mathrm{pH}$ using the ligprep tool in the Schrödinger suite 2016-3 (Schrödinger, LLC, New York, NY, USA)[54]. Parameter files for the excipients were prepared at desired $\mathrm{pH}$ using the antechamber[46] module in Amber 16 in combination with the AM1-BCC[47] charge method. The concentration of excipients was adjusted to $140 \mathrm{mM}$ to match the conditions of the previous SAXS study on Tf stability.[24] Each system was simulated for $100 \mathrm{~ns}$ in duplicates at the same conditions as SAXS.

Different parameters that include preferential interaction coefficient (PIC) and contacts formed between excipients and protein were determined to understand at the molecular level the conformational preferences for $\mathrm{PO}$ or $\mathrm{HO}$ in the presence of excipients and varying salt concentrations and to map potential sites on the protein surface where salt ions and excipients might bind.

\section{Preferential interaction coefficient and interaction hotspot region}

Preferential interaction coefficient $\left(\Gamma_{23}\right)$ was used as a measure of preferential interactions between the additives and protein. $\Gamma_{23}$ defines the overall accumulation of additives on the protein surface, which is defined as follows[55] 


$$
\Gamma_{23}=\left\langle n_{3}^{I I}-n_{1}^{I I}\left(\frac{n_{3}^{I}}{n_{1}^{1}}\right)\right\rangle
$$

where superscript I represent a bulk region, which is outside of the protein vicinity. Superscript II represents a local region around the protein surface. Angled brackets \langle\rangle denote an ensemble average, and $n$ denotes the number of specific additives. Subscripts 1, 2, and 3 stand for water, protein, and additives, respectively. Positive $\Gamma_{23}$ implies favorable protein-excipient interactions, and vice-versa when $\Gamma_{23}$ is negative. A cutoff of $8 \AA$ was used to differentiate local from the bulk region.[56] To estimate $\Gamma_{23}$, the trajectories from the production runs were divided into 5 ns time intervals each containing 50 frames. An average $\Gamma_{23}$ was calculated for each $5 \mathrm{~ns}$ time interval, and uncertainties in $\Gamma_{23}$ are reported as the standard error of the means.[56]

\section{RESULTS AND DISCUSSION}

\section{Effect of $\mathbf{p H}$}

Tf releases ferric ions at endosomal $\mathrm{pH} 5.6$ by opening the iron-binding site.[57] Previously performed SAXS experiments identified different proportions of PO and HO conformers depending on the $\mathrm{pH}$.[24] The equilibrium between $\mathrm{HO}$ and $\mathrm{PO}$ conformations shifts towards the PO conformer with decreasing $\mathrm{pH}$. At $\mathrm{pH} 5, \sim 55 \% \mathrm{PO}$ and $\sim 23 \% \mathrm{HO}$ were present, whereas, this equilibrium shifts towards the $\mathrm{HO}$ conformer (90\%) as the $\mathrm{pH}$ was increased to 6.5 and above. Several factors such as N-lobe and C-lobe interactions and change in protonation states of iron coordinating residues influence the conformational changes that lead to ferric ion release from the lobe.[30,58] Studies carried out previously have shown that the electrostatic field around $\mathrm{Fe}^{3+}$ is important for the opening of the lobes.[59] Therefore, the electrostatic potential surface was calculated using the $\mathrm{H}++$ server[38] considering the most representative structure extracted from clustering of the MD trajectory. Using agglomerative hierarchical clustering approach, the conformations generated over time were grouped into distinct clusters depending on the conformational similarity.[60]

At $\mathrm{pH}$, the electrostatic potential surfaces of $\mathrm{PO}$ and $\mathrm{HO}$ were similar (Figure 2A, B). However, the titratable residues (D63, Y95, Y188, K206, H249, K296, D392, Y426, Y517, K534, H585) coordinating with $\mathrm{Fe}^{3+}$ were susceptible to changes in their protonation states (Figure 1). Change in the protonation state of these residues is known to initiate the conformational change since the 
corresponding residues lose the ability to coordinate to iron.[30,31,58] The simulations reveal that at $\mathrm{pH}$, the protonation state of Y95 and Y188 fluctuate between being protonated and deprotonated (on the hydroxyl group) during the $100 \mathrm{~ns}$ simulation. During the course of the simulations, Y188 drifted away from the iron, indicating that Y188 is involved in ferric ion release from the N-lobe (Figure S1). This is in line with previous studies which indicated that the opening of the N-lobe is triggered by the protonation of Y188.[61] Further, K206, which is part of the "dilysine trigger", is protonated most of the time during the simulation at $\mathrm{pH} 5$, whereas, it remains deprotonated at $\mathrm{pH} 6.5$ and 8. Previously, it has been shown that protonation of one of the lysine residues constituting the "dilysine trigger" initiates conformational change for N-lobe opening[62]. Additionally, root mean square fluctuations (RMSFs) of the lobes are slightly higher at $\mathrm{pH} 5$ as compared to $\mathrm{pH} 8$ (Figure 3). The N-lobe has higher fluctuation compared to the C-lobe (Figure 3) owing to the presence of one extra cystine in the $\mathrm{C}$-lobe. The $\mathrm{N}$-lobe fluctuation is rather global; however, we see that local fluctuations are higher around the first shell iron coordinating residues, which may initialize iron release from $\mathrm{N}$-lobe.

Ideally, at physiological pH, Tf exists in the closed (HO) form. During the simulation of the HO at pH 6.5 and 8, neither Y95 nor Y188 was protonated, and Lys206 was deprotonated, keeping the dilysine-bridge intact and no drastic change in conformation was encountered. Root mean square deviation (RMSD) of Tf fluctuated within $4 \AA$ (Figure S2). These findings were in agreement with the SAXS results wherein HO conformation existed in high proportion at $\mathrm{pH} 6.5$ and 8.[24] This further supports the view that $\mathrm{HO}$ conformation is preferred since Y188 and K206 are deprotonated in the $\mathrm{HO}$ conformer. Additionally, at $\mathrm{pH}$ 6.5, electrostatics surface plots of the representative PO conformer extracted from the simulations indicated that PO is unfavorable due to negative chargecharge repulsion at the interface linker region (Figure 2C), which leads to an increase in the hinge distance (end-to-end linker residues 331-339) to 23+/-0.5 $\AA$. On the other hand, the interface appeared less positive in the $\mathrm{HO}$ conformation with an average hinge distance of $17+/-1.2 \AA$ at $\mathrm{pH}$ 6.5 (Figure 2D). Overall, $\mathrm{pH}$ affects the preference for different conformations. As discussed 
above, $\mathrm{PO}$ conformation is preferred at $\mathrm{pH}$, and with an increase in $\mathrm{pH}$, the electrostatic surface potential changes causing that the Tf structural preference to shift towards HO conformation.

A.

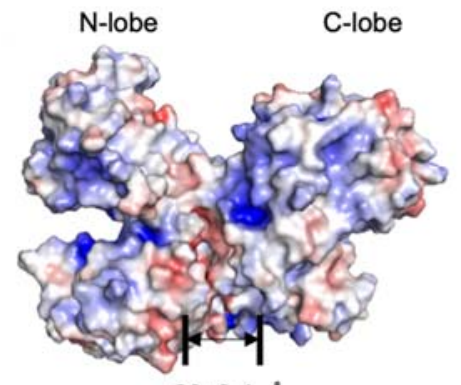

c.

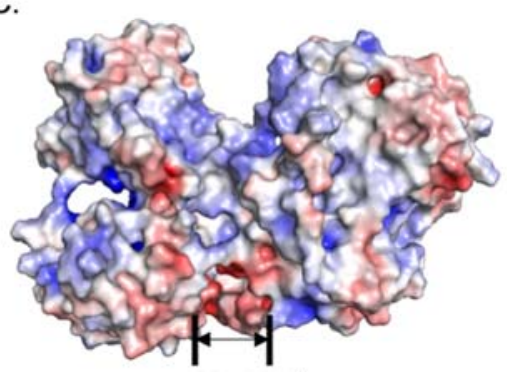

B.

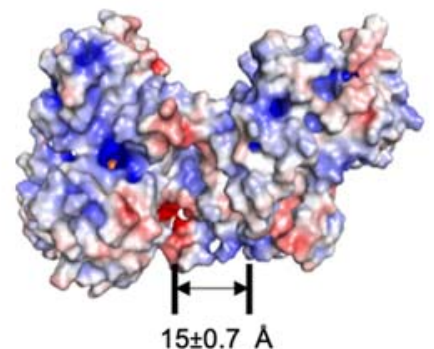

D.

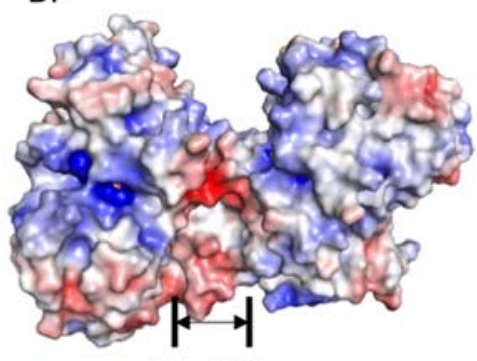

$17 \pm 1.2 \mathrm{~A}$

$23 \pm 0.5 \AA$



Figure 2. Electrostatic potential surfaces calculated for A. PO, pH 5; B. HO, pH 5; C. PO, pH 6.5; D. $\mathrm{HO}, \mathrm{pH}$ 6.5. $\mathrm{H}++$ server was used to generate electrostatic potential surfaces. Red, white, and blue surface colors indicate negative, close to neutral and positive potentials, respectively, as indicated by the color bar. The structures are presentative structures extracted from clustering of the MD trajectory using the agglomerative hierarchical clustering approach.[60] Linker (331-339) distances are shown below each image.
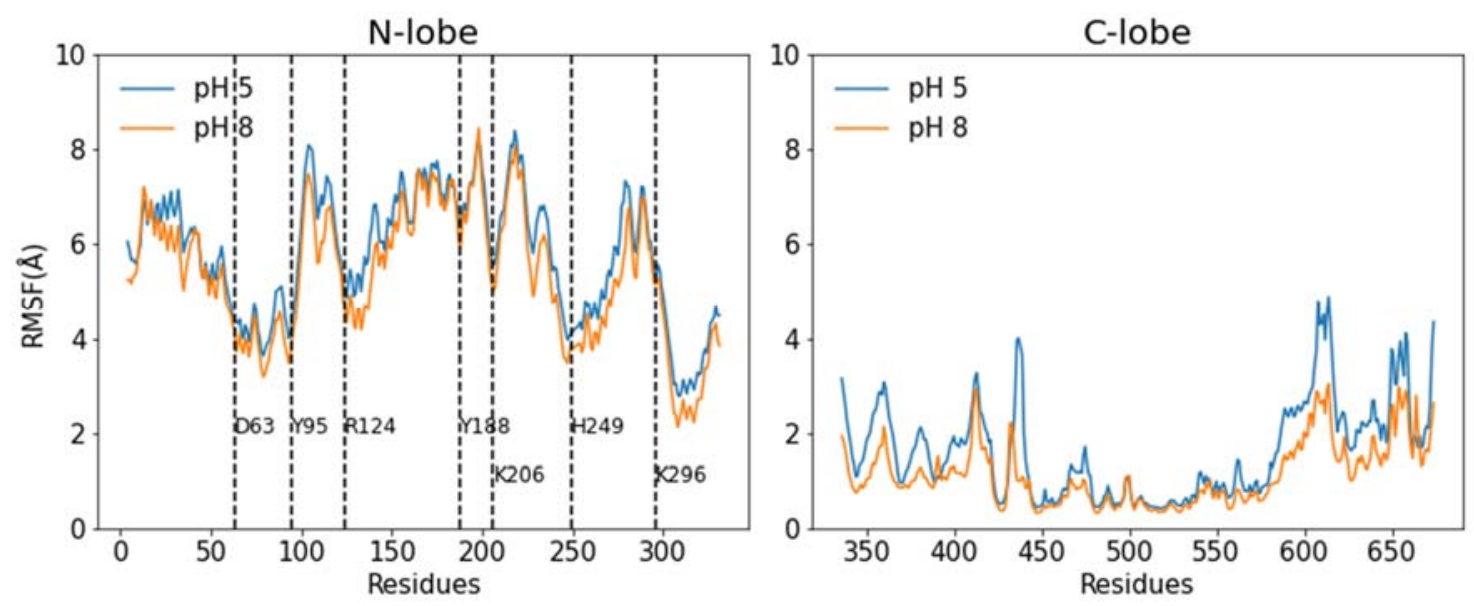
Figure 3. RMSF plots of N-lobe and C-lobe of $\mathrm{HO}$ at $\mathrm{pH} 5.0$ (blue line) and 8.0 (orange line) from the combined analysis of the replicas. N-lobe iron coordinating residues are marked with black dashed lines.

\section{Effect of salt}

Comparative electrostatic surface studies of the PO conformer at $\mathrm{pH} 5$ for varying $\mathrm{NaCl}$ concentrations $(0,70 \mathrm{mM}$, and $140 \mathrm{mM})$ were carried out. It was observed that the iron-binding cleft in the $\mathrm{N}$-lobe had a balance of positive and negative charges at $0 \mathrm{mM} \mathrm{NaCl}$, as opposed to a positively charged surface in the presence of $70 \mathrm{mM} \mathrm{NaCl}$ (Figure 4A, B). Previous studies on the salt effect have shown that binding of chloride ions to Tf has a synergistic effect on the ferric ion release from the lobes.[32,63] Further, R124 has been recognized as a kinetically significant anion binding site that accommodates chloride ions and allosterically communicates with the iron coordinating residues.[64] In our simulation, we see more accumulation of Cl- ions around R124 in PO as suppose to $\mathrm{HO}$ at $\mathrm{pH} 5$ (Figure 5B). In this work, negative PIC values for chloride ions imply that the protein surface is saturated with ions and thus prefers to accumulate into the bulk (Figure 5A and S3A). Further, in Figure 5B, we observe that chloride ions make more contacts with iron coordinating residues in both conformers suggesting initiation of iron release. These stabilizing interactions causes iron to drift away from the coordinating residues in the N-lobe, thus causing its release (Figure 7B).

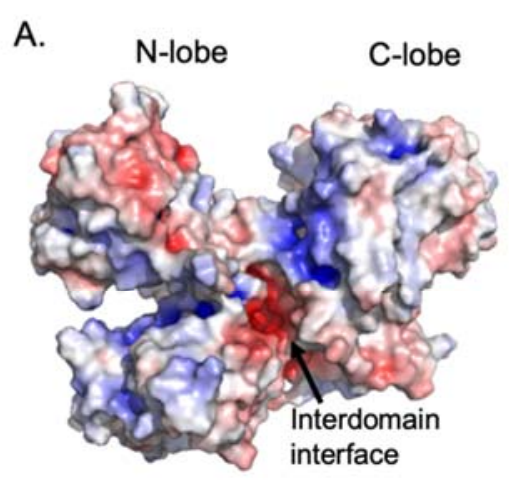

B.

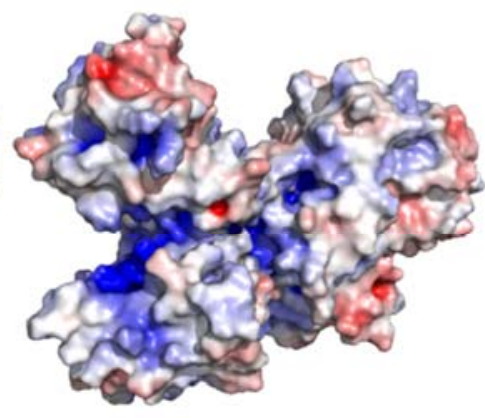

c.

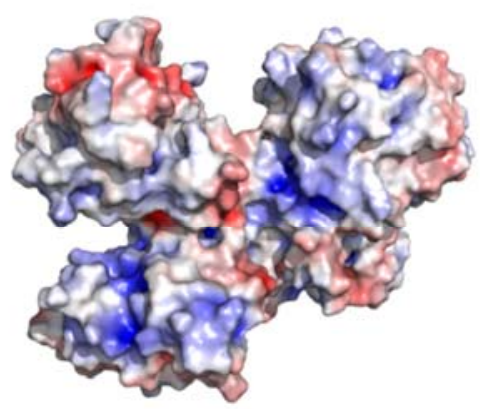

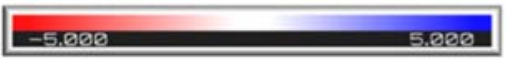

Figure 4. Electrostatics potential surfaces for $\mathrm{PO}$ conformation at $\mathrm{pH} 5$ and $\mathrm{A} .0 \mathrm{mM} \mathrm{NaCl}, \mathrm{B} .70$ $\mathrm{mM} \mathrm{NaCl}$, and C. $140 \mathrm{mM} \mathrm{NaCl}$. The structures are presentative structures extracted from clustering of the MD trajectory using the agglomerative hierarchical clustering approach.[60] 
To conclude, as seen in SAXS experiments[24] at $\mathrm{pH}$ 5, increasing the salt concentration shifts the equilibrium, $\mathrm{PO} \leftrightarrow \mathrm{HO}$, to a higher percentage of PO conformation (from $55 \%$ to $64 \%$ ) reducing the presence of $\mathrm{HO}$ conformation (from $23 \%$ to $3 \%$ ). Further, a strong negatively charged patch around the linker region connecting the $\mathrm{N}$ and $\mathrm{C}$-lobes is seen in the absence of salt (Figure 4A). Electrostatics potential around the interdomain linker region shifts from positive to neutral as salt concentration is increased from 70 to $140 \mathrm{mM} \mathrm{NaCl}$ (Figure $4 \mathrm{~B}, \mathrm{C}$ ), caused by a higher chloride ion accumulation in the interdomain region at $70 \mathrm{mM} \mathrm{NaCl}$ as compared to $140 \mathrm{mM} \mathrm{NaCl}$ (Figure $\mathrm{S} 3 \mathrm{~B}, \mathrm{C})$.

A.

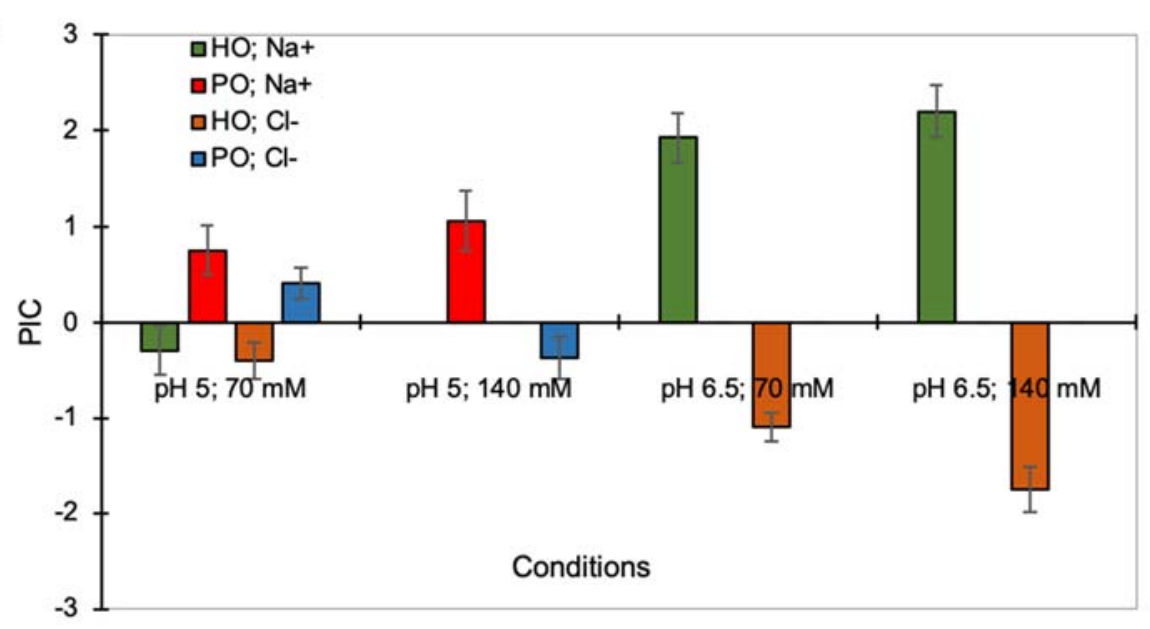

B.
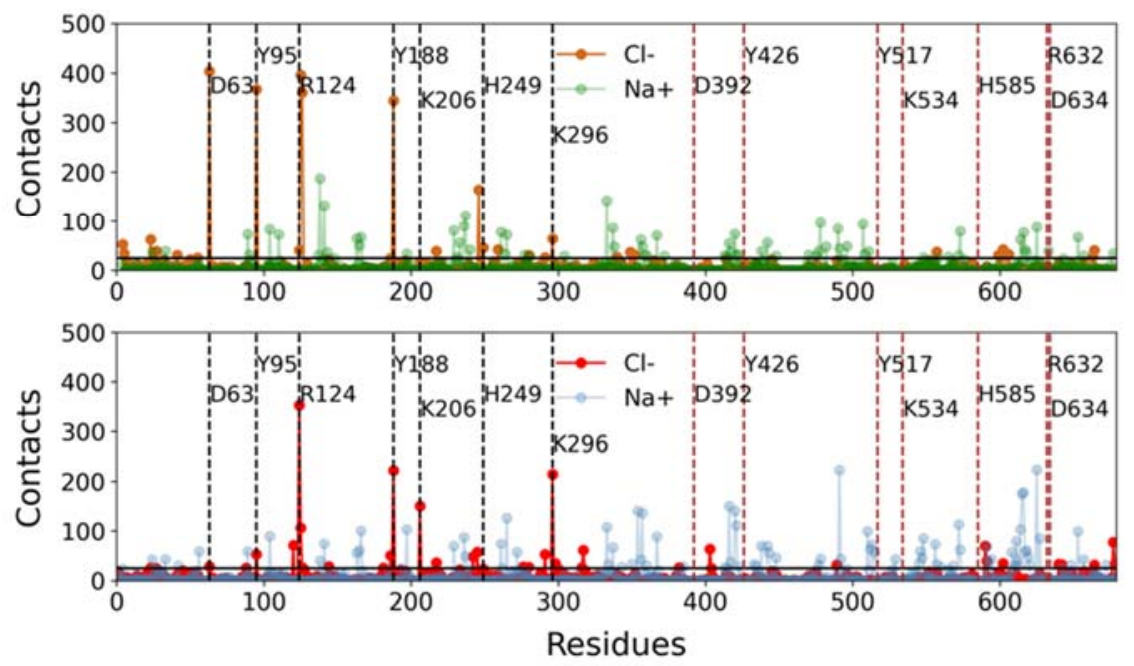

Figure 5. A. PIC values of sodium and chloride ions are shown for the HO and PO conformers at selected conditions corresponding to the conditions used for the SAXS experiments. Positive PIC values imply ongoing salt accumulation on the protein surface or favorable protein-salt interactions while negative values implies saturation of protein surface with salt or unfavorable protein-salt 
interactions. B. Plot showing the number of contacts formed between ions and HO (top panel) and PO (bottom panel) conformers at $\mathrm{pH} 5,70 \mathrm{mM}$, respectively. The black horizontal line is the standard deviation over all formed contacts across all excipients. N-lobe and C-lobe iron coordinating residues are marked with black and red dashed lines, respectively.

For the PO conformer, at pH 5 and $70 \mathrm{mM} \mathrm{NaCl}$, chloride ions strongly interact in the iron-binding cleft of the N-lobe and around the linker region of the protein to balance the positive surface charges in order to stabilize the PO conformer (Figure 5B). At $140 \mathrm{mM} \mathrm{NaCl}$ and (pH 5), the PIC values for chloride ions are lower as compared to $70 \mathrm{mM}$. This implies that saturation of the protein surface with chloride ions has already reached at $70 \mathrm{mM} \mathrm{NaCl}$ and a further increase in salt concentration to $140 \mathrm{mM}$ leads to salt accumulation in the bulk (Figure 5A, S3). On the other hand, even though the PIC values for the sodium ions are positive, the absence of sodium ion interaction on the N-lobe iron-binding site imply that sodium may not contribute to the opening of the N-lobe (Figure 5). Unspecific sodium ion binding is observed on the protein surface.

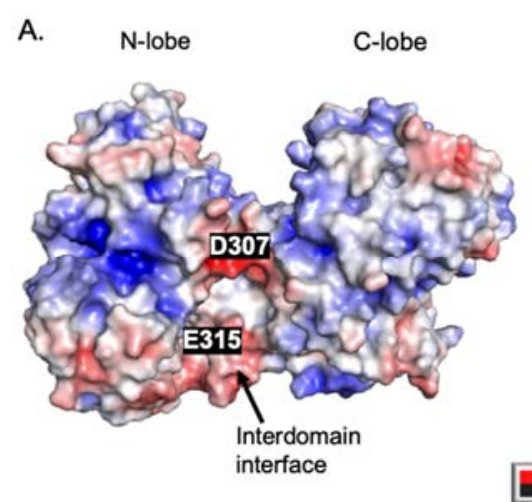

B.

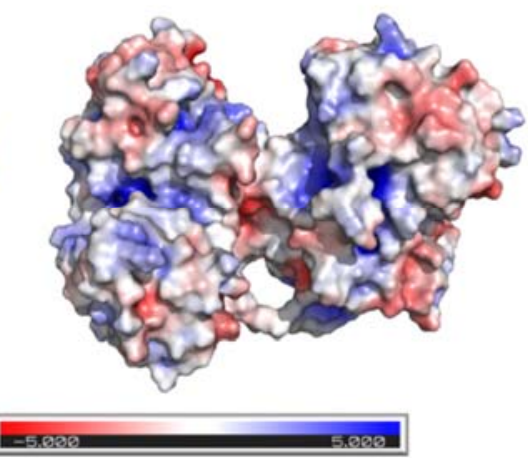

C.

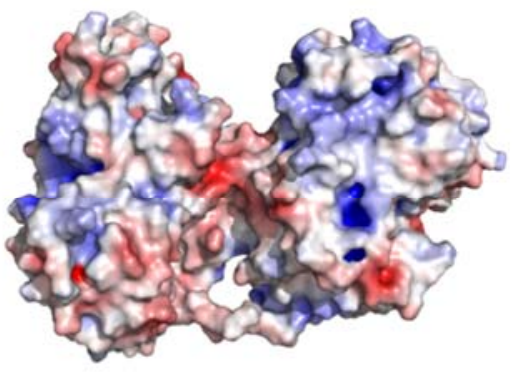

Figure 6. Electrostatic potential surfaces for $\mathrm{HO}$ conformation at $\mathrm{pH} 6.5$ and $\mathrm{A} .0 \mathrm{mM} \mathrm{NaCl}, \mathrm{B}$. $70 \mathrm{mM} \mathrm{NaCl}$ and C. $140 \mathrm{mM} \mathrm{NaCl}$. The structures are presentative structures extracted from clustering of the MD trajectory using the agglomerative hierarchical clustering approach.[60]

Unlike at $\mathrm{pH} 6.5$, at $\mathrm{pH}$, the shift of the equilibrium from $\mathrm{HO}$ to $\mathrm{PO}$ conformation with the addition of salt can be explained by two effects i.e. change in the protonation states of Y188 and K206; and binding of chloride ions in the iron-binding site of N-lobe (Figure 5B). According to SAXS results, Tf is mainly present in the $\mathrm{HO}$ conformation (90\%) at $\mathrm{pH} 6.5$, and the addition of $\mathrm{NaCl}$ does not promote the PO conformation.[24] At pH 6.5 and $0 \mathrm{mM} \mathrm{NaCl}$, the interface region (around residues D307, E315) is negatively charged (Figure 6A). However, already at 70mM 
$\mathrm{NaCl}$, there is a balance of positive and negative charges around the interdomain interface region (Figure 6B, C). As reflected by the PIC data (Figure 5A), the trend for chloride and sodium PIC values for $\mathrm{HO}$ conformation is similar for the two salt concentrations at $\mathrm{pH} 6.5$. At $70 \mathrm{mM} \mathrm{NaCl}$, there exists chloride interactions with protein around the iron binding site of N-lobe (Y188, R124, H246, K296; Figure S4), though, not as strong as at pH 5 (Figure 5B). Up to the concentration of $140 \mathrm{mM}$, accumulation of chloride ions is not seen in the iron binding site of N-lobe (Figure S4, top panel). Thus, it shows that the added salt accumulates into the bulk, which is reflected as a high negative PIC value for chloride (Figure 5A, S4). Conversely, sodium ions does not interact with N-lobe iron-binding site but binds unspecifically to the other parts on the protein surface, leading to positive PIC values (Figure 5A, S4). On the whole, $\mathrm{HO}$ is stabilized at $\mathrm{pH} 6.5$ by accumulation of salt in the bulk and away from iron binding residues in the N-lobe.

\section{Effect of excipients}

In the following section, the term excipient is used in a wider range that also includes the buffering agents as excipients[65] since the tested buffer systems not only regulate shifts in $\mathrm{pH}$, but the buffer components also interact with Tf and might affect Tf's conformational stability. Generally, different conformations are stabilized by the respective excipients by binding to different sites in PO and HO conformers. This is expected due to the different physicochemical properties of the excipients. Besides, at $\mathrm{pH} 5$, arginine and histidine carry a charge of +1 each whereas acetate has a charge of -1 . Moreover, arginine has a hydrophobic fatty acid chain and histidine has aromatic properties. Figure 7 depicts the PIC values calculated at selected physicochemical conditions corresponding to the conditions used for the SAXS experiments. The general trend is that similar PICs are observed for arginine and histidine at pH 5 irrespective of the two conformers (HO, PO). Conversely, the negatively charged acetate remains mainly in the bulk phase at $\mathrm{pH} 5$ as indicated by the negative PIC value (Figure 7A). Arginine and histidine make more contacts per residue as suppose to acetate in the HO conformer (Figure 8). At pH 5, distances of the coordinating residues to iron were monitored (based on the center of mass) to see if the addition of excipients can induce conformational changes in Tf(Figure 7B). The increase in the distance in the HO conformer causes iron to drift away from Arg124 to initiate iron release from the N-lobe but no significant change in the $\mathrm{Fe}^{3+}-\mathrm{R} 124$ distance was observed when acetate was added to the solution (Figure 7B,C). However, the distances between iron and Y95/Y188 increased in the presence of acetate and 
histidine (Figure 7B,C). All in all, the increase in the distance of N-lobe coordinating residues to the iron could cause release of iron.


Figure 7. A. PIC $\left(\Gamma_{23}\right)$ values were determined from the simulations of the PO and HO conformers at selected physicochemical conditions corresponding to the SAXS experimental conditions. For phosphate, PIC value is only shown for $\mathrm{pH} 6.5$ in order to compare the PIC values with that of histidine. B. Bar plot showing the difference in the mean distances between iron and the coordinating residues, dislysine bridge for the $\mathrm{HO}$ conformer for different excipients at $140 \mathrm{mM}$, pH 5. Mean distances are calculated by subtracting each distance from the respective distance of the minimized starting structure. The error bar is the standard error of the block from the block averaging of the different systems.[66] C. Distance between iron and N-lobe iron coordinating residues $(\mathrm{R} 124, \mathrm{Y} 188)$ as a function of time for the $\mathrm{HO}$ conformer at $\mathrm{pH}$ 5. Black dashed line is the distance in the minimized HO structure.

Excipients interact with several patches on the protein surface of the $\mathrm{HO}$ and PO conformers (Figure 8, S6). Arginine and histidine bind more strongly in the HO and PO conformers as compared to acetate (Figure 8, S6). The differences in the excipient interactions could be the reason 
for a higher fraction of PO conformation in case of histidine and arginine, but a lower fraction for acetate.[24] However, the common loop regions in the HO conformer where the excipients bind consist of residues D416-D420 (near opening of C-lobe for iron release), and residues E89-T93 (N'-N" connecting loop in N-lobe) (Figure 8). Furthermore, at $\mathrm{pH} 5$ and in the presence of excipients, RMSF is higher depending on the excipient as suppose to in the absence, around the iron binding site in N-lobe including in the two loop regions. This could imply plausible conformational changes to initiate the opening of the N-lobe (Figure S5). These interactions are particularly interesting as they are absent at pH 6.5 for histidine and phosphate (Figure 9). Thus, these specific interactions could possibly initiate conformational changes as reflected in RMSF and change in distances between iron and coordinating residues leading to HO to PO conversion at $\mathrm{pH} 5$ (Figure 7B). In conclusion, the differences in the extent of excipient interactions with Tf could explain the variations in the fraction of PO conformer seen in SAXS experiments.[24]
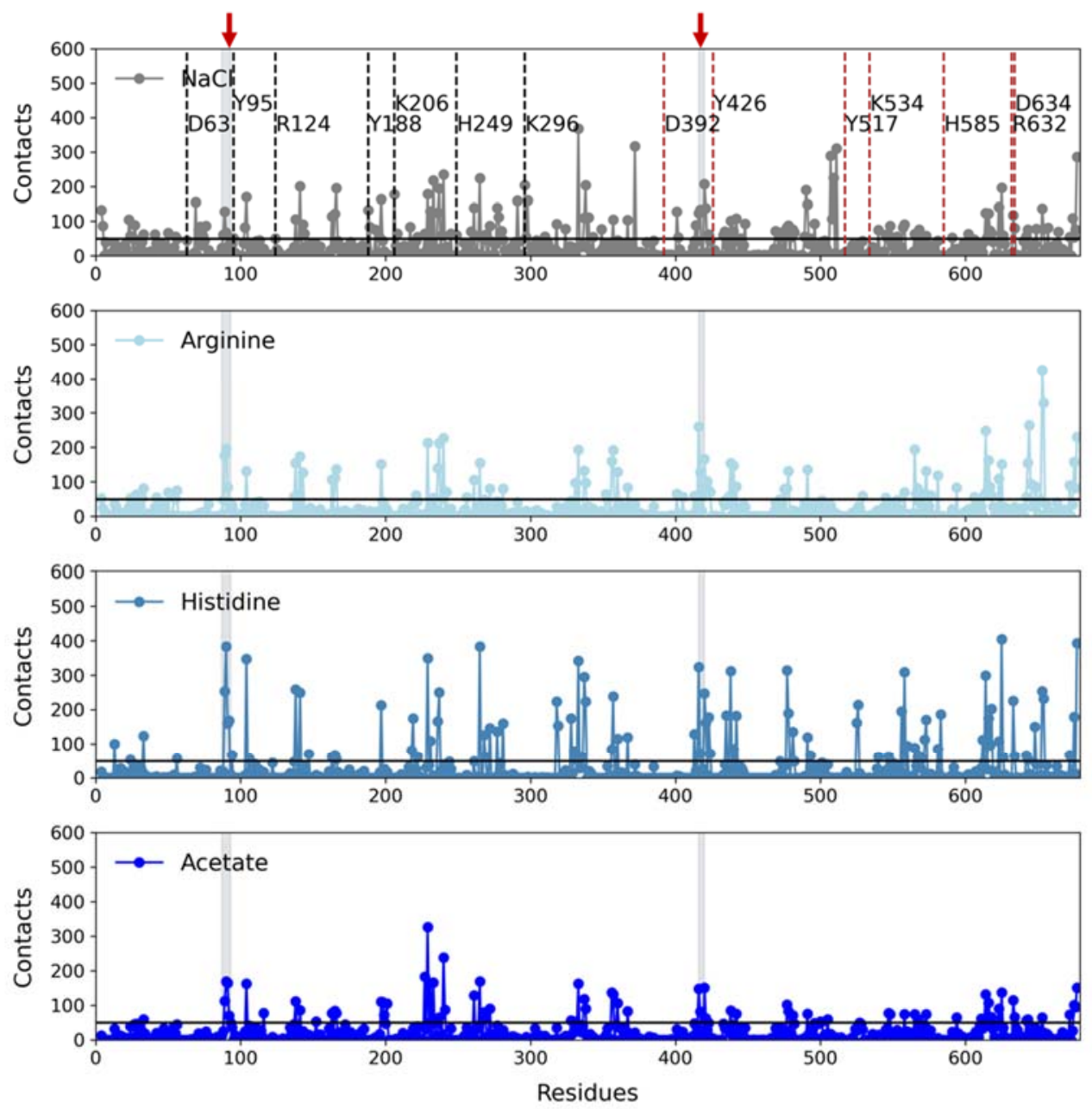
Figure 8. Plot showing number of contacts formed between the excipients and HO conformer at $\mathrm{pH}$ 5. Results are shown for excipient concentrations of $140 \mathrm{mM}$. Gray shaded regions with a red arrow are the two loops $(89-93,416-420)$. The black horizontal line is the standard deviation over contacts considering all four excipients. N-lobe and C-lobe iron coordinating residues are marked with black and red dashed lines, respectively.

At pH 6.5, HO conformation is preferred as Y188 and K206 are deprotonated as discussed in the $\mathrm{pH}$ section above. The charge of phosphate and histidine is -2 and 0 , respectively, which makes phosphate more likely to interact with the exposed hydrophilic patches strongly as compared to histidine. Phosphate and histidine interactions in the C-lobe loop region (D416-D420) and N-lobe loop region (E89-T93) are negligible at $\mathrm{pH} 6.5$ for the $\mathrm{HO}$ conformer (Figure 9). The absence of these interactions could explain why $\mathrm{HO}$ conformation is favored at $\mathrm{pH}$ 6.5.[24] Returning to the PIC data (Figure 7), phosphate has a substantially higher value compared to other excipients implying a high preference of phosphate for the protein surface. The differences in PIC values can be used to understand the stabilizing ability of excipients.[24] Generally, at pH 6.5, histidine interacts weakly with the protein surface in many regions (Figure 9) causing stabilization of the HO conformer.[24] Interactions for histidine as an excipient in the loop regions (E89-T93, D416D420) are weaker (Figure 9) than histidine at $\mathrm{pH} 5$ (Figure 8). Conversely, accumulation of phosphate on the protein surface causes destabilization of HO conformer as reflected in RMSF plot and isothermal denaturation experiments (Figure S7).[24]
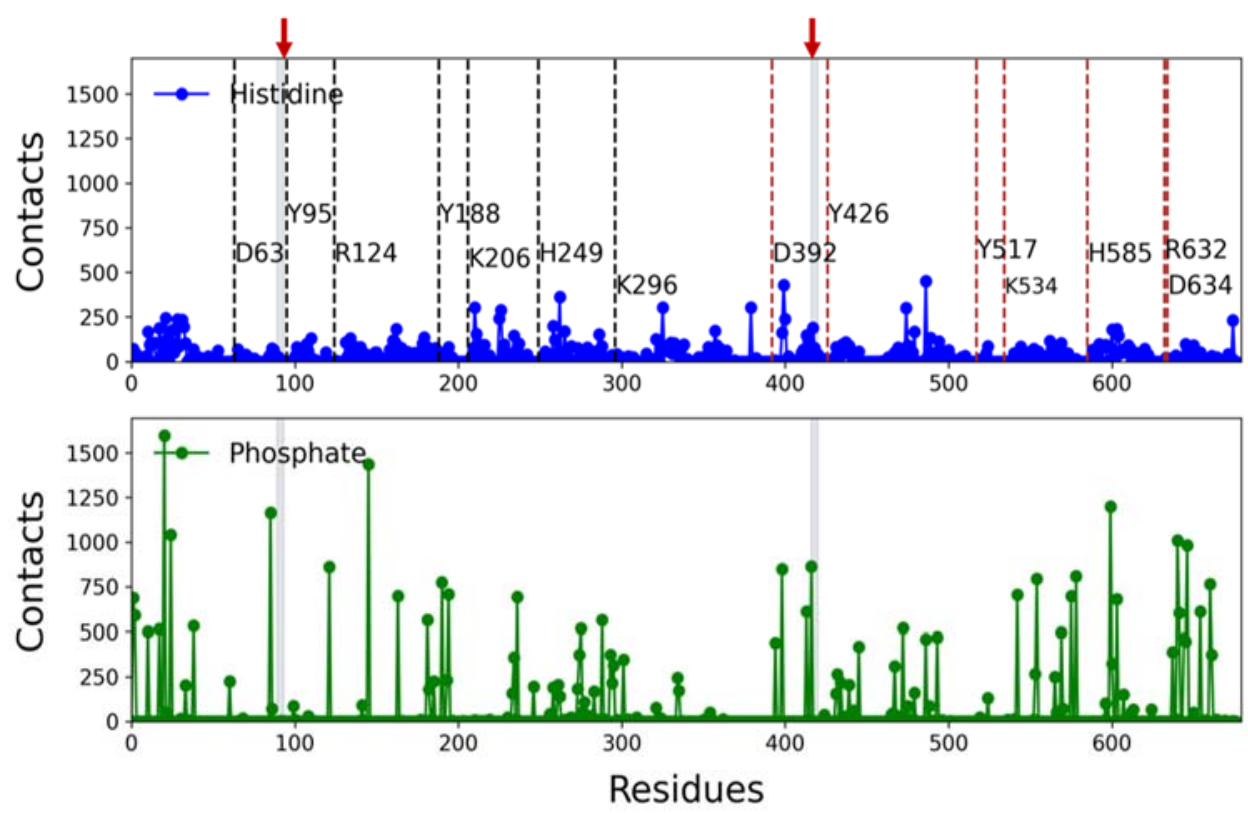
Figure 9. Plot showing number of contacts formed between $\mathrm{HO}$ conformer and excipients (Histidine and phosphate on top and bottom panel, respectively) at pH 6.5, $140 \mathrm{mM}$. Gray shaded regions with a red arrow are the two loops (89-93, 416-420). N-lobe and C-lobe iron coordinating residues are marked with black and red dashed lines, respectively.

\section{CONCLUSIONS}

Human serum transferrin (Tf) can exist in three conformers, a holo form[35], an iron-free apo form[6], and an intermediate form called "partially open[36]". Herein, we have performed MD simulations to investigate the structural properties of the conformers at different physicochemical conditions and the interactions of excipients with the different conformers to map the molecular determinants that determine the preferred conformers observed in SAXS experiments[24]. In this

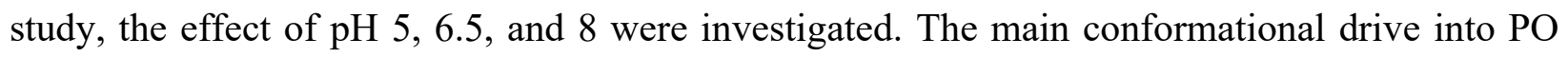
conformation at $\mathrm{pH} 5$ is the protonation states of the iron coordinating residues. Previous studies, as well as our studies, have shown that protonation of Y188 brings about change in the protonation of K206 that eventually leads to conformational changes. From SAXS results, it is observed that at $\mathrm{pH}$ 5, Tf exists predominantly in the PO conformation, and the equilibrium shifts towards the $\mathrm{HO}$ conformer as the $\mathrm{pH}$ increases to 6 and above. Our results indicate that the transition between conformers is driven by the change in protonation states of the N-lobe iron coordinating residues (Y188, K206) and a shift in electrostatic surface potential at the interdomain interface. Subsequently, the effect of $\mathrm{NaCl}$ at 70 and $140 \mathrm{mM}$ on the lobe dynamics were studied. At pH 5 and $70 \mathrm{mM} \mathrm{NaCl}$, it is encountered that chloride ions bind strongly in the $\mathrm{N}$-lobe iron binding site of HO conformer, whereas these interactions are weak at $\mathrm{pH}$ 6.5. The driving force behind the accumulation of the salt in the N-lobe iron binding site is the change in the electrostatic potentials at this region. For $140 \mathrm{mM} \mathrm{NaCl}$, regions surrounding N-lobe iron binding site are saturated and salt accumulates into the bulk away from the protein vicinity. Our results also indicate that depending on the type of excipient conformational changes can be induced. At low $\mathrm{pH}$, arginine and histidine make more contacts with the protein as suppose to acetate due to their different physicochemical properties. All three excipients (arginine, histidine, and acetate) interact in similar loop regions located in the C-lobe (residues D416-D420) and N-lobe (residues E89-T93) of HO conformer. These specific interactions cause conformational changes as reflected in the change in distances between iron and coordinating residues alongside changes in the protonation 
states of Y188 and K206 thus leading to HO to PO transition. Moreover, the addition of arginine and histidine causes Arg124 in the HO conformation to drift away from the iron. Such a movement is not observed in the presence of acetate suggesting that a larger fraction of PO is present in solution (as seen in SAXS) for arginine or histidine compared to acetate. At pH 6.5, histidine is neutral and interacts only weakly with several patches on the protein surface except at the two loop regions (residues D416-D420 and E89-T93), which is otherwise strong in the two loop regions at pH 5 due to +1 charge thus stabilising $\mathrm{PO}$ conformer at low $\mathrm{pH}$. Also, at $\mathrm{pH} 6.5$, phosphate makes more contacts as suppose to histidine due to -2 charge, which might explain the destabilization of of $\mathrm{HO}$ conformer and the destabilizing effect as seen in isothermal denaturation experiments.[24] The computational approach presented can be applied to explore conformational dynamics of other biologics.

\section{AUTHOR INFORMATION}

\section{Corresponding Author}

E-Mail: sowmyaiisc@gmail.com

Phone number: $+45(45252486)$

E-Mail: ghp@kemi.dtu.dk

Phone number: $+45(45252486)$

\section{ORCID}

Sowmya Indrakumar: 0000-0002-5144-3261

Alina Kulakova: 0000-0002-5994-1759

Pernille Harris: 0000-0002-6806-4903

Günther H.J. Peters: 0000-0001-9754-2663

\section{AUTHOR CONTRIBUTIONS}

S.I. performed the simulations and drafted the manuscript, G.H.J.P. contributed to the design of the computational study and discussion of the results. A.K. and P.H. contributed to the design of SAXS experiments and discussion of the SAXS results. All authors contributed to the writing of the manuscript. 


\section{ACKNOWLEDGMENTS}

This study was funded by a project part of the EU Horizon 2020 Research and Innovation program under the Marie Skłodowska-Curie grant agreement No 675074 - "Protein-excipient Interactions and Protein-Protein Interactions in formulation" (PIPPI); http://www.pippi.kemi.dtu.dk. We used VMD 1.9.3 [67], pymol 1.8.4.2[68] and jupyter notebook plugins[69] for performing analyses or making the graphical images. Simulations were performed on the CPU/GPU cluster at DTU Chemistry and the High Performance Computing cluster at DTU. DanScatt is acknowledged for funding the SAXS trip. EMBL P12 DESY and EMBL B29 ESRF are acknowledged for providing beam time for performing the SAXS experiments, and Albumedix Ltd is acknowledged for kindly providing recombinant transferrin.

\section{ABBREVIATIONS \\ MD, molecular dynamics; Tf, human serum transferrin; PO, partially open form of Tf; HO, closed form of Tf; AP, open form of Tf; PIC, preferential interaction coefficients; SAXS, small angle X- ray scattering; RMSF, root mean square fluctuation; RMSD, root mean square deviation; TfR, transferrin receptor; $\mathrm{BCT}$, bicarbonate; $\mathrm{PDB}$, protein data bank}




\section{REFERENCES}

[1] M.C.-M. Chung, Stucture and function of transferrin, Biochem. Educ. 12 (1984) 146-154. https://doi.org/10.1016/0307-4412(84)90118-3.

[2] P. Aisen, I. Listowsky, Iron Transport and Storage Proteins, Annu. Rev. Biochem. 49 (1980) 357-393. https://doi.org/10.1146/annurev.bi.49.070180.002041.

[3] H. Kawabata, Transferrin and transferrin receptors update, Free Radic. Biol. Med. 133 (2019) 46-54. https://doi.org/10.1016/j.freeradbiomed.2018.06.037.

[4] M. Fujii, I. Yoshino, M. Suzuki, T. Higuchi, S. Mukai, T. Aoki, T. Fukunaga, Y. Sugimoto, Y. Inoue, J. Kusuda, T. Saheki, M. Sato, S. Hayashi, M. Tamaki, T. Sugano, Primary culture of chicken hepatocytes in serum-free medium ( $\mathrm{pH} 7.8$ ) secreted albumin and transferrin for a long period in free gas exchange with atmosphere., Int. J. Biochem. Cell Biol. 28 (1996) 1381-91. http://www.ncbi.nlm.nih.gov/pubmed/9022295.

[5] J.H. Jandl, J.H. Katz, The Plasma-to-Cell Cycle of Transferrin, J. Clin. Invest. 42 (1963) 314-326. https://doi.org/10.1172/JCI104718.

[6] J. Wally, P.J. Halbrooks, C. Vonrhein, M.A. Rould, S.J. Everse, A.B. Mason, S.K. Buchanan, The Crystal Structure of Iron-free Human Serum Transferrin Provides Insight into Inter-lobe Communication and Receptor Binding, J. Biol. Chem. 281 (2006) 2493424944. https://doi.org/10.1074/jbc.M604592200.

[7] J. Wally, S.K. Buchanan, A structural comparison of human serum transferrin and human lactoferrin, BioMetals. 20 (2007) 249-262. https://doi.org/10.1007/s10534-006-9062-7.

[8] P. Aisen, R. Aasa, B.G. Malmström, T. Vänngård, Bicarbonate and the binding of iron to transferrin., J. Biol. Chem. 242 (1967).

[9] M. Boshuizen, K. van der Ploeg, L. von Bonsdorff, B.J. Biemond, S.S. Zeerleder, R. van Bruggen, N.P. Juffermans, Therapeutic use of transferrin to modulate anemia and conditions of iron toxicity, Blood Rev. 31 (2017) 400-405. https://doi.org/10.1016/j.blre.2017.07.005.

[10] H. Sun, H. Li, P.J. Sadler, Transferrin as a Metal Ion Mediator, Chem. Rev. 99 (1999) 2817-2842. https://doi.org/10.1021/cr980430w.

[11] H. Li, Z.M. Qian, Transferrin/transferrin receptor-mediated drug delivery, Med. Res. Rev. 22 (2002) 225-250. https://doi.org/10.1002/med.10008.

[12] R.J.S. McGonigle, V. Parsons, Aluminium-induced anaemia in haemodialysis patients, 
Nephron. 39 (1985) 1-9.

[13] H. Li, H. Sun, Z.M. Qian, The role of the transferrin-transferrin-receptor system in drug delivery and targeting, Trends Pharmacol. Sci. 23 (2002) 206-209. https://doi.org/10.1016/S0165-6147(02)01989-2.

[14] Z.M. Qian, Targeted Drug Delivery via the Transferrin Receptor-Mediated Endocytosis Pathway, Pharmacol. Rev. 54 (2002) 561-587. https://doi.org/10.1124/pr.54.4.561.

[15] A.A. Alexander-Bryant, W.S. Vanden Berg-Foels, X. Wen, Bioengineering Strategies for Designing Targeted Cancer Therapies, in: Adv. Cancer Res., 2013: pp. 1-59. https://doi.org/10.1016/B978-0-12-407173-5.00002-9.

[16] K.C. Gatter, G. Brown, I.S. Trowbridge, R.E. Woolston, D.Y. Mason, Transferrin receptors in human tissues: their distribution and possible clinical relevance., J. Clin. Pathol. 36 (1983) 539-545. https://doi.org/10.1136/jcp.36.5.539.

[17] K.B. Johnsen, A. Burkhart, F. Melander, P.J. Kempen, J.B. Vejlebo, P. Siupka, M.S. Nielsen, T.L. Andresen, T. Moos, Targeting transferrin receptors at the blood-brain barrier improves the uptake of immunoliposomes and subsequent cargo transport into the brain parenchyma, Sci. Rep. 7 (2017) 10396. https://doi.org/10.1038/s41598-017-11220-1.

[18] B. Chiou, E.H. Neal, A.B. Bowman, E.S. Lippmann, I.A. Simpson, J.R. Connor, Pharmaceutical iron formulations do not cross a model of the human blood-brain barrier, PLoS One. 13 (2018) e0198775. https://doi.org/10.1371/journal.pone.0198775.

[19] S. Frokjaer, D.E. Otzen, Protein drug stability: a formulation challenge, Nat. Rev. Drug Discov. 4 (2005) 298-306. https://doi.org/10.1038/nrd1695.

[20] M.E.M. Cromwell, E. Hilario, F. Jacobson, Protein aggregation and bioprocessing, AAPS J. 8 (2006) E572-E579. https://doi.org/10.1208/aapsj080366.

[21] K.L. Zapadka, F.J. Becher, A.L. Gomes dos Santos, S.E. Jackson, Factors affecting the physical stability (aggregation) of peptide therapeutics, Interface Focus. 7 (2017) 20170030. https://doi.org/10.1098/rsfs.2017.0030.

[22] E.Y. Chi, S. Krishnan, T.W. Randolph, J.F. Carpenter, Physical stability of proteins in aqueous solution: Mechanism and driving forces in nonnative protein aggregation, Pharm. Res. 20 (2003) 1325-1336. https://doi.org/10.1023/A:1025771421906.

[23] T.J. Kamerzell, R. Esfandiary, S.B. Joshi, C.R. Middaugh, D.B. Volkin, Protein-excipient interactions: Mechanisms and biophysical characterization applied to protein formulation 
development, Adv. Drug Deliv. Rev. 63 (2011) 1118-1159.

https://doi.org/10.1016/j.addr.2011.07.006.

[24] A. Kulakova, S. Indrakumar, P. Sønderby, L. Gentiluomo, W. Streicher, D. Roessner, W. Frieß, G.H.J. Peters, P. Harris, Small angle X-ray scattering and molecular dynamic simulations provide molecular insight for stability of recombinant human transferrin, J. Struct. Biol. X. 4 (2020) 100017. https://doi.org/10.1016/j.yjsbx.2019.100017.

[25] A. Kulakova, S. Indrakumar, P. Sønderby Tuelung, S. Mahapatra, W.W. Streicher, G.H.J. Peters, P. Harris, Albumin-neprilysin fusion protein: understanding stability using small angle X-ray scattering and molecular dynamic simulations, Sci. Rep. 10 (2020) 10089. https://doi.org/10.1038/s41598-020-67002-9.

[26] S. Indrakumar, M. Zalar, N. Tschammer, C. Pohl, A. Nørgaard, W. Streicher, P. Harris, A.P. Golovanov, G.H.J. Peters, Development of a fast screening method for selecting excipients in formulations using MD simulations, NMR and microscale thermophoresis, Eur. J. Pharm. Biopharm. 158 (2021) 11-20. https://doi.org/10.1016/j.ejpb.2020.10.015.

[27] C. Pohl, M. Zalar, I. El Bialy, S. Indrakumar, G.H.J. Peters, W. Friess, A.P. Golovanov, W.W. Streicher, A. Noergaard, P. Harris, The Effect of Point Mutations on the Biophysical Properties of an Antimicrobial Peptide: Development of a Screening Protocol for Peptide Stability Screening, Mol. Pharm. 17 (2020) 3298-3313. https://doi.org/10.1021/acs.molpharmaceut.0c00406.

[28] S. Indrakumar, M. Zalar, C. Pohl, A. Nørgaard, W. Streicher, P. Harris, A.P. Golovanov, G.H.J. Peters, Conformational Stability Study of a Therapeutic Peptide Plectasin Using Molecular Dynamics Simulations in Combination with NMR, J. Phys. Chem. B. 123 (2019) 4867-4877. https://doi.org/10.1021/acs.jpcb.9b02370.

[29] L. Gentiluomo, H. Svilenov, D. Augustijn, I.E. Bialy, M.L. Greco, A. Kulakova, S. Indrakumar, S. Mahapatra, M. Morales, C. Pohl, A. Roche, A. Tosstorff, J.P. Derrick, R. Curtis, A. Nørgaard, T.A. Khan, G.H.J. Peters, Å. Rinnan, W. Streicher, C. van der Walle, S. Uddin, G. Winter, D. Roessner, P. Harris, W. Frieß, Advancing therapeutic protein discovery and development through comprehensive computational and biophysical characterization, Submitted. (2019).

[30] J.I. Mujika, B. Escribano, E. Akhmatskaya, J.M. Ugalde, X. Lopez, Molecular dynamics simulations of iron- and aluminum-loaded serum transferrin: Protonation of tyr188 is 
necessary to prompt metal release, Biochemistry. 51 (2012) 7017-7027. https://doi.org/10.1021/bi300584p.

[31] H. Abdizadeh, A.R. Atilgan, C. Atilgan, Detailed molecular dynamics simulations of human transferrin provide insights into iron release dynamics at serum and endosomal $\mathrm{pH}$, J. Biol. Inorg. Chem. 20 (2015) 705-718. https://doi.org/10.1007/s00775-015-1256-4.

[32] H. Abdizadeh, A.R. Atilgan, C. Atilgan, Mechanisms by Which Salt Concentration Moderates the Dynamics of Human Serum Transferrin, J. Phys. Chem. B. 121 (2017) 4778-4789. https://doi.org/10.1021/acs.jpcb.7b02380.

[33] H. Abdizadeh, A.R. Atilgan, C. Atilgan, B. Dedeoglu, Computational approaches for deciphering the equilibrium and kinetic properties of iron transport proteins, Metallomics. 9 (2017) 1513-1533. https://doi.org/10.1039/C7MT00216E.

[34] D.H. Hamilton, I. Turcot, A. Stintzi, K.N. Raymond, Large cooperativity in the removal of iron from transferrin at physiological temperature and chloride ion concentration, JBIC J. Biol. Inorg. Chem. 9 (2004) 936-944. https://doi.org/10.1007/s00775-004-0592-6.

[35] N. Noinaj, N.C. Easley, M. Oke, N. Mizuno, J. Gumbart, E. Boura, A.N. Steere, O. Zak, P. Aisen, E. Tajkhorshid, R.W. Evans, A.R. Gorringe, A.B. Mason, A.C. Steven, S.K. Buchanan, Structural basis for iron piracy by pathogenic Neisseria, Nature. 483 (2012) 53-58. https://doi.org/10.1038/nature10823.

[36] N. Yang, H. Zhang, M. Wang, Q. Hao, H. Sun, Iron and bismuth bound human serum transferrin reveals a partially-opened conformation in the N-lobe, Sci. Rep. 2 (2012) 999. https://doi.org/10.1038/srep00999.

[37] J.C. Dewan, B. Mikami, M. Hirose, J.C. Sacchettini, Structural evidence for a pHsensitive dilysine trigger in the hen ovotransferrin N-lobe: Implications for transferrin iron release, Biochemistry. 32 (1993) 11963-11968. https://doi.org/10.1021/bi00096a004.

[38] J.C. Gordon, J.B. Myers, T. Folta, V. Shoja, L.S. Heath, A. Onufriev, H++: a server for estimating pKas and adding missing hydrogens to macromolecules, Nucleic Acids Res. 33 (2005) W368-W371. https://doi.org/10.1093/nar/gki464.

[39] D.A. Case, T.E. Cheatham, T. Darden, H. Gohlke, R. Luo, K.M. Merz, A. Onufriev, C. Simmerling, B. Wang, R.J. Woods, The Amber biomolecular simulation programs, J. Comput. Chem. 26 (2005) 1668-1688. https://doi.org/10.1002/jcc.20290.

[40] J. Mongan, D.A. Case, J.A. McCammon, Constant $\mathrm{pH}$ molecular dynamics in generalized 
Born implicit solvent, J. Comput. Chem. 25 (2004) 2038-2048.

https://doi.org/10.1002/jcc.20139.

[41] V. Maingi, V. Jain, P. V. Bharatam, P.K. Maiti, Dendrimer building toolkit: Model building and characterization of various dendrimer architectures, J. Comput. Chem. 33 (2012) 1997-2011. https://doi.org/10.1002/jcc.23031.

[42] K. Lindorff-Larsen, S. Piana, K. Palmo, P. Maragakis, J.L. Klepeis, R.O. Dror, D.E. Shaw, Improved side-chain torsion potentials for the Amber ff99SB protein force field., Proteins. 78 (2010) 1950-8. https://doi.org/10.1002/prot.22711.

[43] M.W. Mahoney, W.L. Jorgensen, A five-site model for liquid water and the reproduction of the density anomaly by rigid, nonpolarizable potential functions, J. Chem. Phys. 112 (2000) 8910-8922. https://doi.org/10.1063/1.481505.

[44] P. Li, K.M. Merz, Taking into Account the Ion-Induced Dipole Interaction in the Nonbonded Model of Ions, J. Chem. Theory Comput. 10 (2014) 289-297. https://doi.org/10.1021/ct400751u.

[45] M.T. Panteva, G.M. Giambaşu, D.M. York, Comparison of structural, thermodynamic, kinetic and mass transport properties of $\mathrm{Mg} 2+$ ion models commonly used in biomolecular simulations, J. Comput. Chem. 36 (2015) 970-982. https://doi.org/10.1002/jcc.23881.

[46] J. Wang, R.M. Wolf, J.W. Caldwell, P.A. Kollman, D.A. Case, Development and testing of a general amber force field, J. Comput. Chem. 25 (2004) 1157-1174. https://doi.org/10.1002/jcc.20035.

[47] A. Jakalian, D.B. Jack, C.I. Bayly, Fast, efficient generation of high-quality atomic charges. AM1-BCC model: II. Parameterization and validation, J. Comput. Chem. 23 (2002) 1623-1641. https://doi.org/10.1002/jcc.10128.

[48] J.-P. Ryckaert, G. Ciccotti, H.J.C. Berendsen, Numerical integration of the cartesian equations of motion of a system with constraints: molecular dynamics of n-alkanes, J. Comput. Phys. 23 (1977) 327-341. https://doi.org/10.1016/0021-9991(77)90098-5.

[49] T. Darden, D. York, L. Pedersen, Particle mesh Ewald: An N·log(N) method for Ewald sums in large systems, J. Chem. Phys. 98 (1993) 10089-10092. https://doi.org/10.1063/1.464397.

[50] R.W. Pastor, B.R. Brooks, A. Szabo, An analysis of the accuracy of Langevin and 
molecular dynamics algorithms, Mol. Phys. 65 (1988) 1409-1419.

https://doi.org/10.1080/00268978800101881.

[51] H.J.C. Berendsen, J.P.M. Postma, W.F. van Gunsteren, A. DiNola, J.R. Haak, Molecular dynamics with coupling to an external bath, J. Chem. Phys. 81 (1984) 3684-3690. https://doi.org/10.1063/1.448118.

[52] S. Kim, J. Chen, T. Cheng, A. Gindulyte, J. He, S. He, Q. Li, B.A. Shoemaker, P.A. Thiessen, B. Yu, L. Zaslavsky, J. Zhang, E.E. Bolton, PubChem 2019 update: improved access to chemical data, Nucleic Acids Res. 47 (2019) D1102-D1109. https://doi.org/10.1093/nar/gky1033.

[53] J.J. Irwin, T. Sterling, M.M. Mysinger, E.S. Bolstad, R.G. Coleman, ZINC: A Free Tool to Discover Chemistry for Biology, J. Chem. Inf. Model. 52 (2012) 1757-1768. https://doi.org/10.1021/ci3001277.

[54] G. Madhavi Sastry, M. Adzhigirey, T. Day, R. Annabhimoju, W. Sherman, Protein and ligand preparation: parameters, protocols, and influence on virtual screening enrichments, J. Comput. Aided. Mol. Des. 27 (2013) 221-234. https://doi.org/10.1007/s10822-0139644-8.

[55] D. Shukla, C. Shinde, B.L. Trout, Molecular Computations of Preferential Interaction Coefficients of Proteins, J. Phys. Chem. B. 113 (2009) 12546-12554.

https://doi.org/10.1021/jp810949t.

[56] S. Indrakumar, M. Zalar, C. Pohl, A. Nørgaard, W. Streicher, P. Harris, A.P. Golovanov, G.H.J. Peters, Conformational Stability Study of a Therapeutic Peptide Plectasin Using Molecular Dynamics Simulations in Combination with NMR, J. Phys. Chem. B. 123 (2019) 4867-4877. https://doi.org/10.1021/acs.jpcb.9b02370.

[57] A.N. Steere, S.L. Byrne, N.D. Chasteen, A.B. Mason, Kinetics of iron release from transferrin bound to the transferrin receptor at endosomal $\mathrm{pH}$, Biochim. Biophys. Acta Gen. Subj. 1820 (2012) 326-333. https://doi.org/10.1016/j.bbagen.2011.06.003.

[58] B.E. Eckenroth, A.N. Steere, N.D. Chasteen, S.J. Everse, A.B. Mason, How the binding of human transferrin primes the transferrin receptor potentiating iron release at endosomal pH, Proc. Natl. Acad. Sci. 108 (2011) 13089-13094. https://doi.org/10.1073/pnas.1105786108.

[59] D.A. Lee, J.M. Goodfellow, The pH-Induced Release of Iron from Transferrin 
Investigated with a Continuum Electrostatic Model, Biophys. J. 74 (1998) 2747-2759. https://doi.org/10.1016/S0006-3495(98)77983-4.

[60] A. Wolf, K.N. Kirschner, Principal component and clustering analysis on molecular dynamics data of the ribosomal L11·23S subdomain, J. Mol. Model. 19 (2013) 539-549. https://doi.org/10.1007/s00894-012-1563-4.

[61] J.I. Mujika, B. Escribano, E. Akhmatskaya, J.M. Ugalde, X. Lopez, Molecular Dynamics Simulations of Iron- and Aluminum-Loaded Serum Transferrin: Protonation of Tyr188 Is Necessary To Prompt Metal Release, Biochemistry. 51 (2012) 7017-7027. https://doi.org/10.1021/bi300584p.

[62] A.N. Luck, A.B. Mason, Transferrin-Mediated Cellular Iron Delivery, Curr Top Membr. 69 (2012) 3-35. https://doi.org/10.1016/B978-0-12-394390-3.00001-X.

[63] Q.Y. He, A.B. Mason, V. Nguyen, R.T.A. MacGillivray, R.C. Woodworth, The chloride effect is related to anion binding in determining the rate of iron release from the human transferrin N-lobe, Biochem. J. 350 (2000) 909-915. https://doi.org/10.1042/bj3500909.

[64] H. Abdizadeh, A.R. Atilgan, C. Atilgan, Mechanisms by Which Salt Concentration Moderates the Dynamics of Human Serum Transferrin, J. Phys. Chem. B. 121 (2017) 4778-4789. https://doi.org/10.1021/acs.jpcb.7b02380.

[65] T.J. Zbacnik, R.E. Holcomb, D.S. Katayama, B.M. Murphy, R.W. Payne, R.C. Coccaro, G.J. Evans, J.E. Matsuura, C.S. Henry, M.C. Manning, Role of Buffers in Protein Formulations, J. Pharm. Sci. 106 (2017) 713-733. https://doi.org/10.1016/j.xphs.2016.11.014.

[66] A. Grossfield, D.M. Zuckerman, Chapter 2 Quantifying Uncertainty and Sampling Quality in Biomolecular Simulations, in: 2009: pp. 23-48. https://doi.org/10.1016/S15741400(09)00502-7.

[67] W. Humphrey, A. Dalke, K. Schulten, VMD: Visual molecular dynamics, J. Mol. Graph. 14 (1996) 33-38. https://doi.org/10.1016/0263-7855(96)00018-5.

[68] W.L. DeLano, The PyMOL Molecular Graphics System, Version 1.8, Schrödinger LLC. (2002). https://doi.org/citeulike-article-id:240061.

[69] T. Kluyver, B. Ragan-kelley, F. Pérez, B. Granger, M. Bussonnier, J. Frederic, K. Kelley, J. Hamrick, J. Grout, S. Corlay, P. Ivanov, D. Avila, S. Abdalla, C. Willing, Jupyter Notebooks - a publishing format for reproducible computational workflows, Position. 
bioRxiv preprint doi: https://doi.org/10.1101/2022.01.28.478130; this version posted January 28, 2022. The copyright holder for this preprint (which was not certified by peer review) is the author/funder. All rights reserved. No reuse allowed without permission.

Power Acad. Publ. Play. Agents Agendas. (2016) 87-90. https://doi.org/10.3233/978-161499-649-1-87. 


\title{
Supplementary material for Dynamics of Human
} Serum Transferrin in Varying Physicochemical

\section{Conditions Explored by Using Molecular Dynamics}

\section{Simulations}

\author{
Sowmya Indrakumar ${ }^{1, a^{*}}$, Alina Kulakova ${ }^{1, b}$, Pernille Harris ${ }^{1, b}$, and Günther H. J. Peters ${ }^{1 *}$ \\ ${ }^{1}$ Technical University of Denmark, Department of Chemistry, 2800 Kgs. Lyngby, Denmark, \\ ${ }^{a}$ Biomolecular Sciences, University of Copenhagen, 2100 Copenhagen, Denmark, ${ }^{b}$ Department \\ of Chemistry, University of Copenhagen, 2100 Copenhagen, Denmark
}

*Email: sowmya.indrakumar@bio.ku.dk Phone number: +45(45252486);

*Email: ghp@kemi.dtu.dk, Phone number: +45(45252486) 


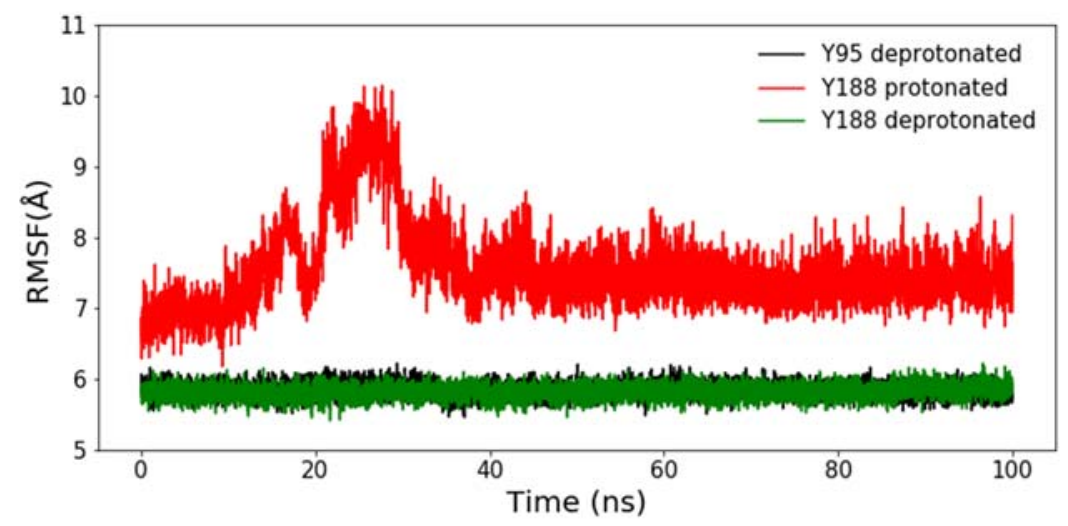

Figure S1. Distance between iron and coordinating Tyr residues at pH 5.0 for HO conformation. Y188 and Y95 were titrated during the simulations, and only Y188 moves away from iron due its protonation (red curve), whereas Y95 stays close to iron (black curve). Additionally, as a test case in another independent simulation, Y188 was kept deprotonated (fixed; green curve) throughout the simulation; it shows that Y188 remains close to the iron (green curve). This demonstrates the role of protonation of Y188 in iron release at $\mathrm{pH} 5$.

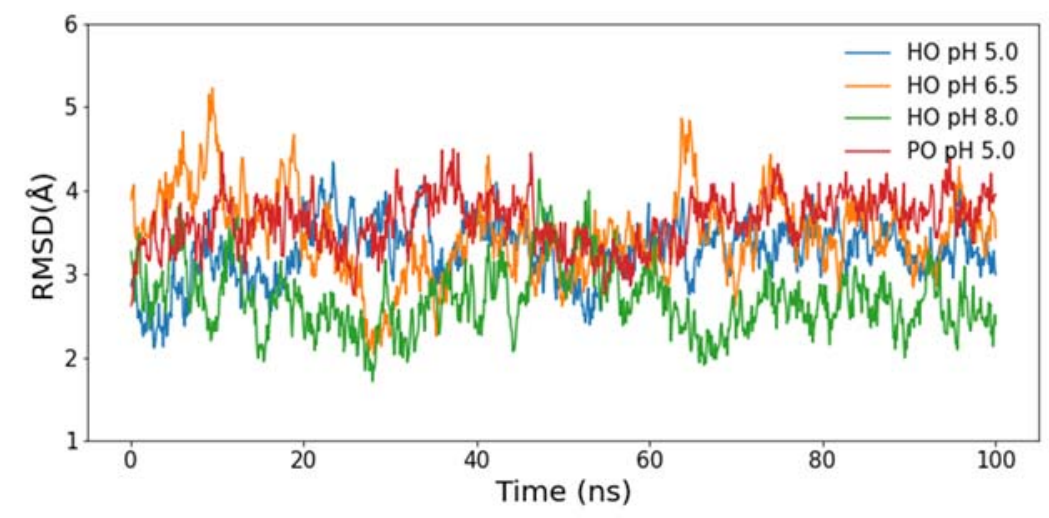

Figure S2. RMSD plot for the different simulated systems. 
A.
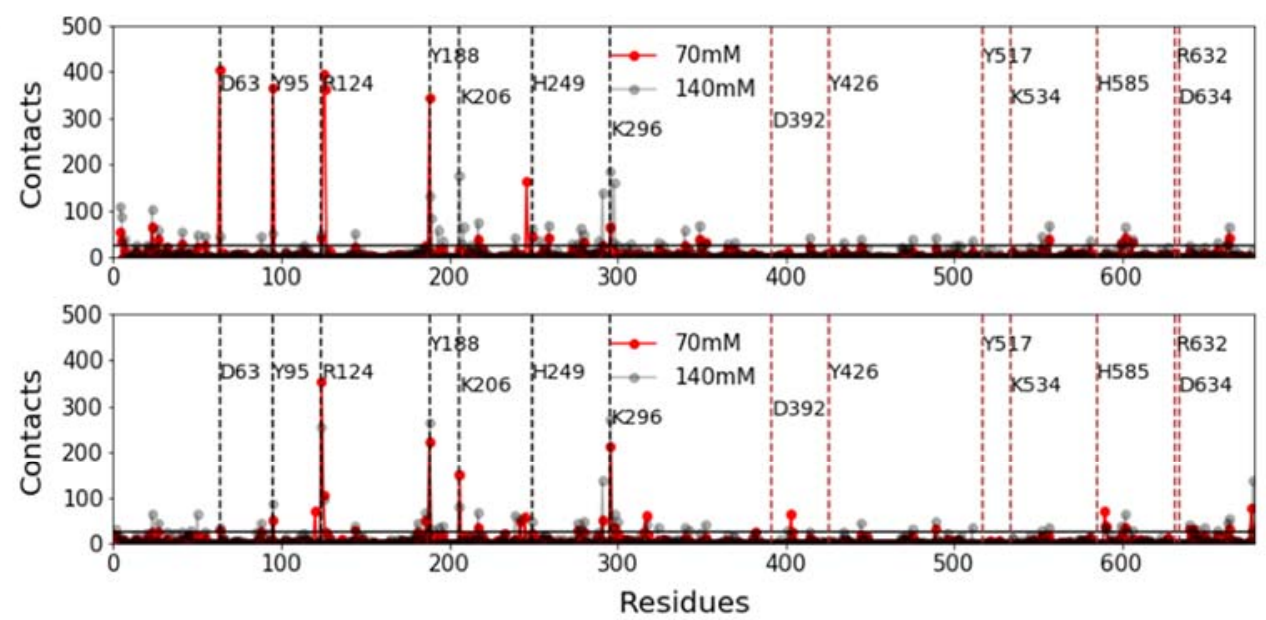

B.
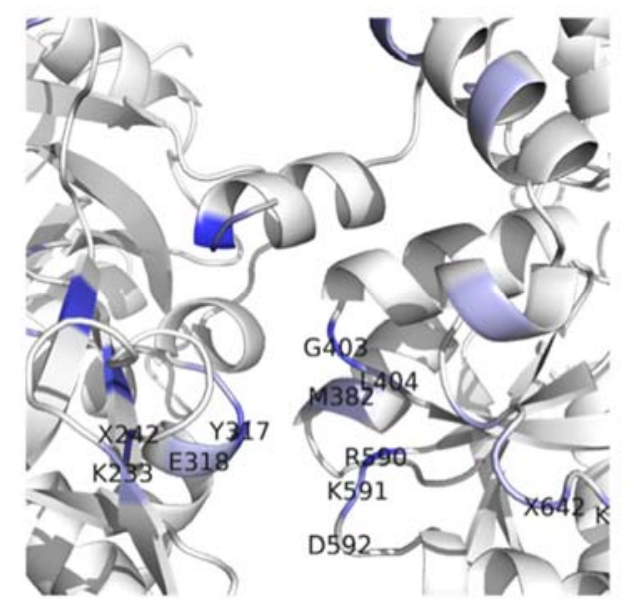

C.
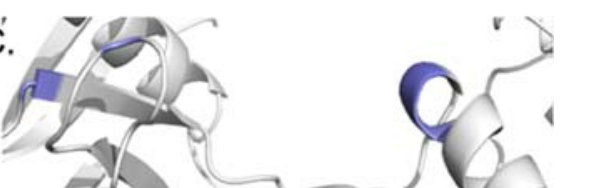

$P\left(I_{\text {score }}\right)$

Min. $\longrightarrow$ Max.

Figure S3. A. Plot showing number of contacts formed between chloride ions and HO (top panel) and PO (bottom panel) conformers at $\mathrm{pH} 5,70 \mathrm{mM}$ and $140 \mathrm{mM}$, respectively. Black horizontal line is the standard deviation over contacts determined for $\mathrm{HO}$ and $\mathrm{PO}$ at the two salt conditions. $\mathrm{N}$-lobe and $\mathrm{C}$-lobe iron coordinating residues are marked with black and red dashed lines, respectively. B. Structure showing subdomain interface of PO conformation colored based on the

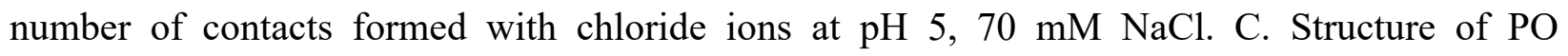
conformation colored based on the number of contacts formed with chloride ions at $\mathrm{pH} 5,140 \mathrm{mM}$ $\mathrm{NaCl}$. 

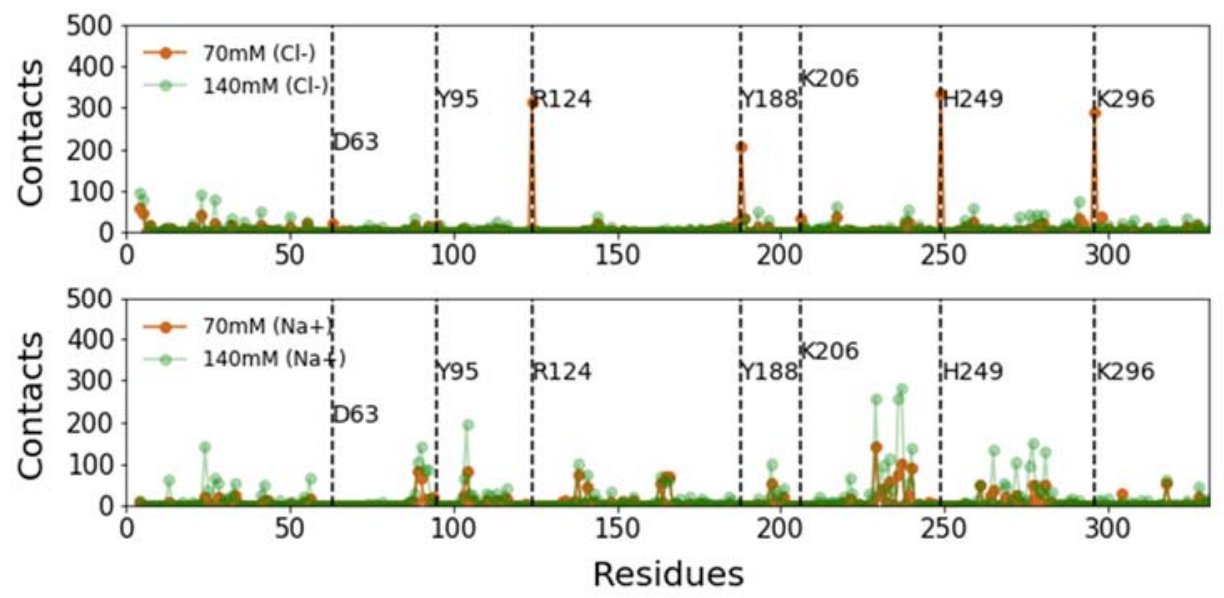

Figure S4. Plot showing number of contacts formed at $\mathrm{pH} 6.5$ between $\mathrm{HO}$ conformer and 70 $\mathrm{mM}$ and $140 \mathrm{mM}$ chloride ions (top panel) and $70 \mathrm{mM}$ and $140 \mathrm{mM}$ sodium ions (bottom). $\mathrm{N}-$ lobe iron coordinating residues are marked with black dashed lines.

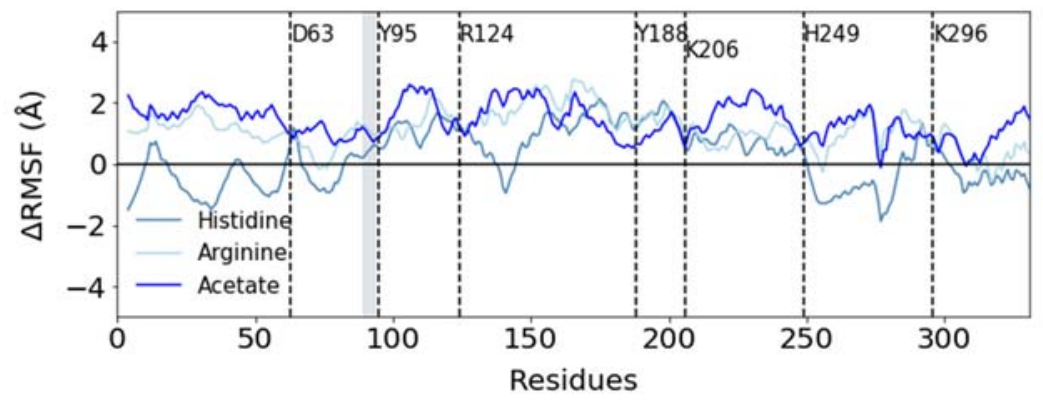

Figure S5. $\triangle \mathrm{RMSF}$ plot for the different excipient system at $\mathrm{pH} 5$ for $\mathrm{HO}$ conformer. RMSF for the different system is subtracted from the system simulated without excipient. Gray shaded regions are the two loops $(89-93,416-420)$. 

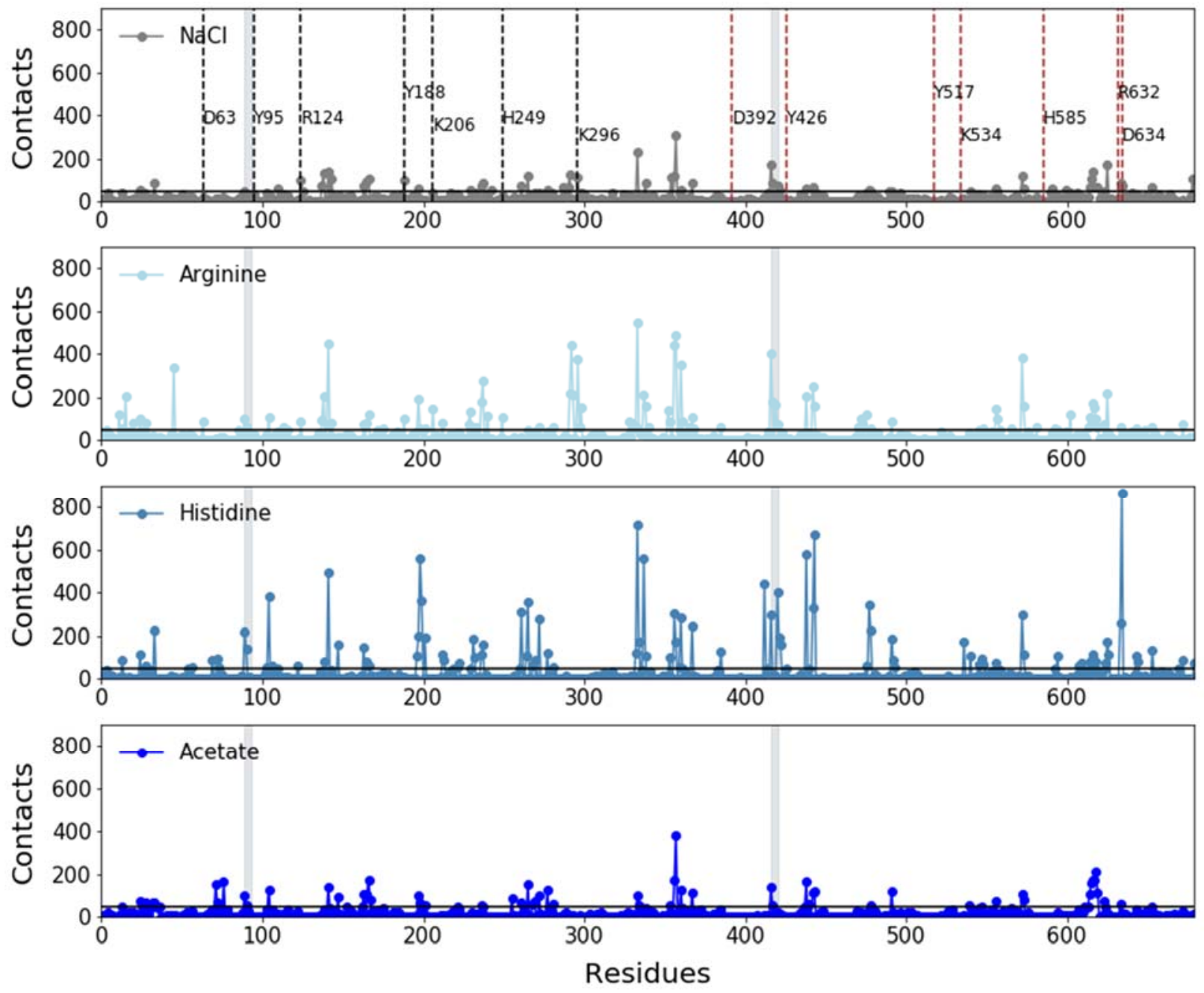

Figure S6. Plot showing number of contacts formed between the excipients and PO conformer at $\mathrm{pH}$ 5. Results are shown for excipient concentration of $140 \mathrm{mM}$. Gray shaded regions are the two loops (89-93, 416-420). Black horizontal line is the standard deviation over contacts considering all four excipients. N-lobe and C-lobe iron coordinating residues are marked with black and red dashed lines, respectively. 


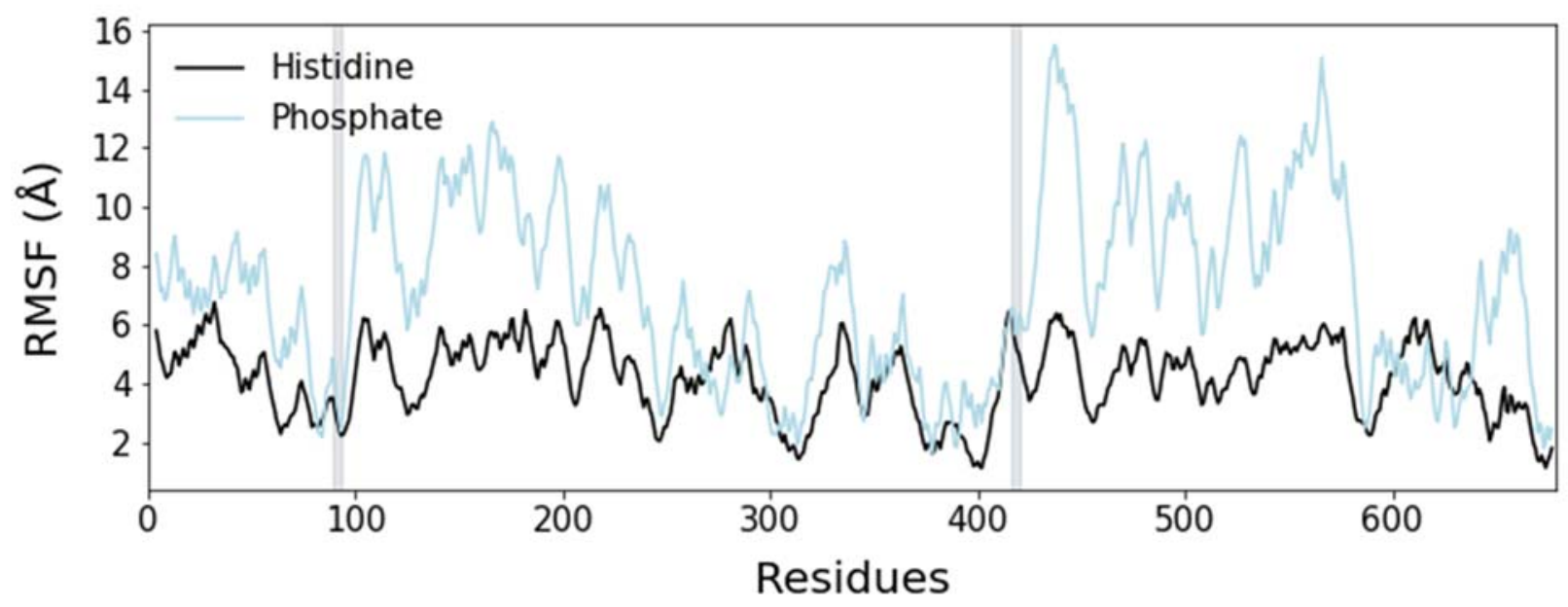

Figure S7. RMSF plot for the different excipient system at $\mathrm{pH} 6.5$ for $\mathrm{HO}$ conformer. Gray shaded regions are the two loops (89-93, 416-420). 
bioRxiv preprint doi: https://doi.org/10.1101/2022.01.28.478130; this version posted January 28, 2022. The copyright holder for this preprint (which was not certified by peer review) is the author/funder. All rights reserved. No reuse allowed without permission. 